\title{
Binaural Tuning of Auditory Units in the Forebrain Archistriatal Gaze Fields of the Barn Owl: Local Organization but No Space Map
}

\author{
Yale E. Cohen and Eric I. Knudsen \\ Department of Neurobiology, Stanford University School of Medicine, Stanford, California 94305-5401
}

We identified a region in the archistriatum of the barn owl forebrain that contains neurons sensitive to auditory stimuli. Nearly all of these neurons are tuned for binaural localization cues. The archistriatum is known to be the primary source of motor-related output from the avian forebrain and, in barn owls, contributes to the control of gaze, much like the frontal eye fields in monkeys.

The auditory region is located in the medial portion of the archistriatum, at the level of the anterior commissure, and is within the region of the archistriatum from which head saccades can be elicited by electrical microstimulation (see preceding companion article, Knudsen et al., 1995). Free-field measurements revealed that auditory sites have large, spatial receptive fields. However, within these large receptive fields, responses are tuned sharply for sound source location. Dichotic measurements showed that auditory sites are tuned broadly for frequency and that the majority are tuned to particular values of interaural time differences and interaural level differences, the principal cues used by barn owls for sound localization. The tuning of sites to these binaural cues is essentially independent of sound level.

The auditory properties of units in the medial archistriatum are similar to those of units in the optic tectum, a structure that also contributes to gaze control. Unlike the optic tectum, however, the auditory region of the archistriatum does not contain a single, continuous auditory map of space. Instead, it is organized into dorsoventral clusters of sites with similar binaural (spatial) tuning. The different representations of auditory space in closely related structures in the forebrain (archistriatum) and midbrain (optic tectum) probably reflect the fact that the forebrain contributes to a wide variety of sensorimotor tasks more complicated than gaze control.

[Key words: sound localization, frontal eye fields, forebrain, superior colliculus, auditory space, archistriatum]

The forebrain contributes to sound localization behavior in barn owls (Knudsen et al., 1993) and in a variety of mammals, including humans, monkeys, cats, and ferrets (for a review, see

Received Oct. 20, 1994; revised Feb. 28, 1995; accepted Mar. 3, 1995

We thank Michael Brainard, Daniel Feldman, Gregory Miller, and Joshua Gold for reviewing the manuscript; Michael Shadlen for advice on the statistical analyses; and Phyllis Knudsen for technical support. This work was supported by grants from the NIH to E.I.K. and the NRSA and the Bank of America-Giannini Foundation to Y.E.C.

Correspondence should be addressed to Yale E. Cohen, Department of Neurobiology, Fairchild Science Building, Stanford University School of Medicine, Stanford, CA 94305-5401.

Copyright $\odot 1995$ Society for Neuroscience $0270-6474 / 95 / 155152-17 \$ 05.00 / 0$
Neff et al., 1975; Clarey et al., 1992). However, the forebrain pathway that mediates sound localization has yet to be identified in any species. Although auditory spatial information is present in the primary auditory projection fields of the forebrain [field $\mathrm{L}$ in owls (Knudsen et al., 1977) and the auditory thalamus and cortex in mammals (see Neff et al., 1975; Clarey et al., 1992)], the subsequent stages of spatial information processing in the forebrain are unknown.

In contrast, in the midbrain, advanced stages of auditory spatial information processing have been well characterized (Knudsen et al., 1987; Konishi et al., 1988). In the external nucleus of the interior colliculus (ICX; Knudsen and Konishi, 1978a; Binns et al., 1992) and in the optic tectum (OT) or superior colliculus (Knudsen, 1982; King and Palmer, 1983; Middlebrooks and Knudsen, 1984; King and Hutchings, 1987; for a review, see Stein and Meredith, 1993), auditory neurons have restricted spatial receptive fields and are organized into single, continuous representations, or maps, of auditory space. In the barn owl, the binaural basis of these spatial receptive fields is known. The tuning of units for interaural time difference (ITD) restricts spatial tuning in azimuth and tuning for interaural level difference (ILD) restricts spatial tuning in elevation, due to a vertical asymmetry in the directional sensitivities of the owl's ears (Payne, 1971; Knudsen et al., 1979; Konishi et al., 1988; Olsen et al., 1989; Brainard et al., 1992). In the ICX and the OT, the value of ITD to which neurons are tuned changes systematically along the rostrocaudal axis of each nucleus, forming maps of azimuth, and the value of ILD to which neurons are tuned changes systematically along the dorsoventral axis of each nucleus, forming maps of elevation (Knudsen and Konishi, 1978a; Moiseff and Konishi, 1981a; Knudsen, 1982; Olsen et al., 1989; Mogdans and Knudsen, 1993).

To learn how the forebrain processes and represents auditory spatial information, we have studied the barn owl, an animal with a highly developed capacity for sound localization (Payne, 1971; Konishi, 1973). Recently, we have identified a forebrain structure, the archistriatum, whose physiological and anatomical properties suggest that it is involved in spatial behavior (see preceding companion article, Knudsen et al., 1995). The archistriatum communicates directly with both the ICX and the OT, structures that are known to contribute to auditory-mediated gaze control (Knudsen et al., 1993; Wagner, 1993). Moreover, electrical microstimulation of sites in a large portion of the archistriatum, the archistriatal gaze fields (AGF), evokes contraversive, saccadic movements of the eyes and head, with kinematics that are similar to those of natural gaze saccades (Knudsen et al., 1995). The AGF projects directly to saccade-generating circuitry in the brainstem tegmentum (in addition to 
projecting to the OT) and can mediate gaze changes independently of the OT. In these respects, the AGF is similar to the frontal eye fields in monkeys (see Goldberg and Segraves, 1989; Bruce, 1990).

Since the archistriatum is involved in spatial behaviors (Knudsen et al., 1995), its neural activity should encode spatial information. Indeed, we found that nearly all of the auditory units in the archistriatum were highly selective for binaural localization cues and that the majority of sites were tuned to specific values of both ITD and ILD. In this study, we explored the functional properties of archistriatal units as they relate to the processing and representation of auditory spatial information.

\section{Materials and Methods}

Data were collected from nine adult barn owls (Tyto alba). The techniques and methodologies used in this study have been described in detail previously (Knudsen, 1985; Olsen et al., 1989).

\section{Preparation}

Owls were prepared for repeated experiments. Prior to electrophysiological recordings, an owl was anesthetized with halothane $(1 \%)$ and nitrous oxide $\left(\mathrm{O}_{2}: \mathrm{NO}_{2}=55: 45\right)$ while a headpiece was cemented to the skull and a craniotomy was made over the OT and the archistriatum. Chloramphenical $(0.5 \%)$ was applied to the brain surface, the craniotomy was sealed with dental acrylic, and the incisions were infused with Xylocaine. After recovery from anesthesia, the animal was returned to its home cage.

On the day of an experiment, the owl was anesthetized with ketamine hydrochloride $(20 \mathrm{mg} / \mathrm{kg}$ body weight $)$ and tranquilized with diazepam $(1 \mathrm{mg} / \mathrm{kg})$. Anesthesia was maintained throughout the experiment with supplemental injections of both ketamine and diazepam. The owl was wrapped in a leather harness, suspended in a prone position inside a sound-attenuated chamber, and secured to a stereotaxic device by its headpiece. The head was positioned using retinal landmarks (the eyes are essentially stationary in the head) so that the visual axes were in the horizontal plane. The dental acrylic was then removed from the craniotomy, and electrophysiological recordings began. At the conclusion of an experiment, chloramphenicol was applied to the brain, the craniotomy was resealed with dental acrylic, and a subcutaneous injection of a $2.5 \%$ dextrose saline solution was administered. Upon recovery from anesthesia, the owl was returned to its home cage.

\section{Free-field stimulation}

Free-field stimuli were presented with a remotely controlled, moveable loudspeaker. The speaker moved on an imaginary sphere centered on the owl's head at a distance of $92 \mathrm{~cm}$. The owl's head was aligned such that the median sagittal and visual planes corresponded to $0^{\circ}$ azimuth and $0^{\circ}$ elevation, respectively, of the speaker moving system. The locations of auditory stimuli are given in degrees left or right of the median sagittal plane (azimuth) and in degrees above or below the visual plane (elevation), as measured from the center of the head.

Free-field acoustic stimuli consisted of computer-generated $50 \mathrm{msec}$ broadband noise $(1.0-12.0 \mathrm{kHz} ; 0 \mathrm{msec}$ rise/fall times) or tone (5 msec rise/fall times) bursts with an interstimulus interval of $1.0 \mathrm{sec}$. The amplitude spectrum of the broadband noise was flat (within $\pm 2 \mathrm{~dB}$ ) from 2 to $12 \mathrm{kHz}$, as measured with a Brüel and Kjaer $12.5 \mathrm{~mm}$ condensor microphone (model 4165) and a spectrum analyzer (Hewlett Packard, model 3582A).

\section{Acoustical measurements of ITD and ILD}

As part of a previous study (Knudsen et al., 1991), interaural differences in the timing and the level of sound were measured for sources located at $10^{\circ}$ intervals in azimuth and elevation across the entire frontal hemifield in five adult barn owls. Broadband noise presented from the moveable loudspeaker was recorded from each ear canal with probe-tube microphones (Bruiel and Kjaer, model 4165). The ITD and ILD values, corresponding to each location in space, that were used in this study to predict dichotic binaural tuning from free-field spatial tuning were based on the averaged values across these five animals.

\section{Dichotic stimulation}

Dichotic stimuli also consisted of noise or tone bursts with the same duration, rise/fall times, and interstimulus intervals as those used for free-ficld stimulation. Howcver, the noise bursts were high-pass filtered at $4.0 \mathrm{kHz}$ to ensure adequate interaural isolation at large ILDs (Moiseff and Konishi, 1981b).

Acoustic stimuli were transduced by Knowles earphones (model 1914) coupled to damping assemblies (BF-1743). The frequency response of the earphones was measured, under free-field conditions, with a Brüel and Kjaer $12.5 \mathrm{~mm}$ condensor microphone and a spectrum analyzer. The frequency response of each earphone was flattened $( \pm 2$ $\mathrm{dB}$ between 4.0 and $12.0 \mathrm{kHz}$ ) by compensatory adjustments in the computer-generated waveforms. The output of the earphones was linear to within $0.2 \mathrm{~dB}$ over a $45 \mathrm{~dB}$ range of input amplitudes.

Each earphone was aligned parallel to the long axis of the ear canal, centered within it, and placed at a fixed distance from the tympanic membrane. Time delays between the two stimulus waveforms were produccd by computcr-calculated shifts of $5-50 \mu \mathrm{sec}$ increments (Olsen et al., 1989). The sound levels produced by the earphones were controlled by programmable attenuators. Frequency-specific differences in sound timing and level between the two earphones ranged up to $3 \mu \mathrm{sec}$ and $2 \mathrm{~dB}$, respectively.

\section{Neurophysiological recordings}

An insulated tungsten microelectrode $(1-3 \mathrm{M} \Omega$ at $1.0 \mathrm{kHz}$ ) was used to record extracellularly from single and multiple units. The electrode was positioned stereotaxically and advanced through the brain with a microdrive while neural activity was monitored on an audio monitor and an oscilloscope. To calibrate the electrode's position in the brain, the electrode was first advanced into the OT. The position of the electrode in the tectum was determined from the location of visual receptive fields (Knudsen, 1982). The auditory region of the archistriatum, the "AAr," was within the area defined as the AGF (Knudsen et al., 1995) and was located approximately $2 \mathrm{~mm}$ rostral, $0.5 \mathrm{~mm}$ lateral, and $3 \mathrm{~mm}$ dorsal of the representation of $0^{\circ}$ azimuth and $0^{\circ}$ elevation in the superficial layers of the OT.

\section{Tuning curve analyses}

The spatial tuning of AAr sites was measured by counting spike discharges to noise bursts presented from various locations at $20-30 \mathrm{~dB}$ above response threshold. Responses were sampled every $5-10^{\circ}$ in azimuth and elevation across a site's receptive field. Net response was quantified by subtracting the number of spikes that occurred during a $100 \mathrm{msec}$ interval prior to stimulus presentation (baseline activity) from the number of spikes occurring during the 100 misec following stimulus onset. The region of space from which the stimulus elicited greater than $50 \%$ of the maximum response was the "best area" of the site. A site's "best azimuth" and "best elevation" were detined by the center of the best area.

Free-field frequency tuning was measured by varying frequencies between 1 and $12 \mathrm{kHz}$, while keeping the sound source at the center of the best area. The "free-field frequency tuning width" was the continunns range of frequencies that elicited greater than $50 \%$ of the maximum response. The center of this range was the site's "free-field best frequency."

Dichotic stimuli were presented at an average binaural level (ABL) of $20 \mathrm{~dB}$ above threshold; $\mathrm{ABL}$ is the sum of the sound levels (in $\mathrm{dB}$ ) at both ears divided by 2 . Tuning curves were generated by presenting series of binaural stimuli consisting of either noise bursts with random sequences of ILDs or ITDs or of tone bursts with random sequences of frequencies. For each tuning curve, at least 10 series of stimuli were presented. The net response to a dichotic stimulus was quantified by subtracting the number of spikes occurring $100 \mathrm{msec}$ prior to stimulus onset (baseline activity) from the number of spikes evoked during the $100 \mathrm{msec}$ following stimulus onset.

The selectivity of AAr sites for ITD was examined over the entire physiological range of ITD values ( $+200 \mu \mathrm{sec}$; Olsen et al., 1989; Knudsen et al., 1991) using the dichotic noise stimulus. ITD tuning curves typically had a strong "primary" peak and smaller "secondary" peaks. Selectivity for ITD was quantified using the three indices defined in Figure 1. The first index, "ITD response modulation," was the difference between a site's largest and smallest response ( $a$ and $b$, respectively, in Fig. 1A), expressed as a percentage of the largest response. The maximum attainable value of ITD and ILD response modulation 
A

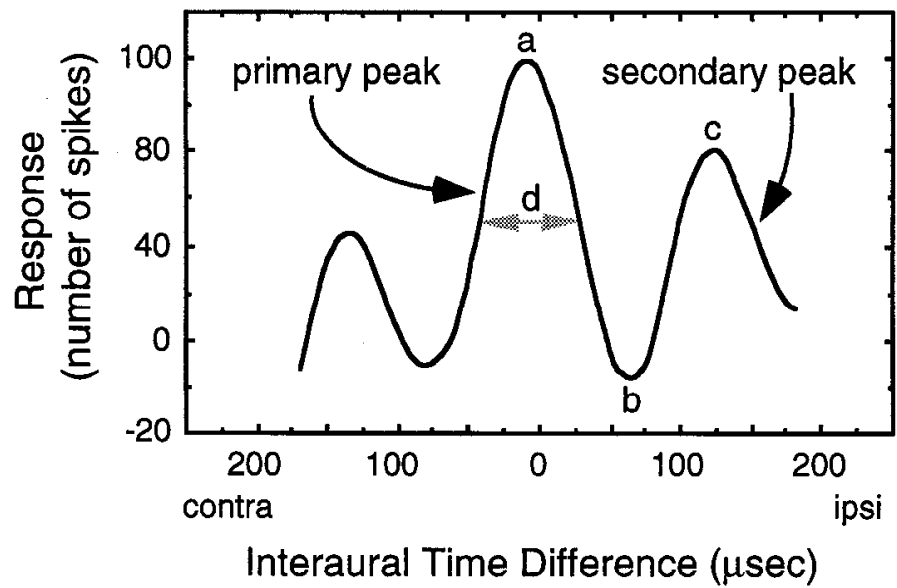

Figure 1. A, Schematized ITD tuning curve illustrating the indices used to quantify ITD selectivity. Responses were based on the number of spikes after subtracting the baseline discharge rate. "ITD response modulation" was defined as the difference between a site's largest $(a)$ and smallest $(b)$ response to an ITD value and was expressed as a percentage of the largest response: $(a-b) / a \times 100$. The "relative size of the secondary peak," was the response at the largest secondary peak $(c)$ relative to the response at the primary peak $(a): c / a \times 100$. "ITD tuning width" was the range of ITD values that elicited greater than $50 \%$ of the largest response $(d)$. "Best ITD" was the center of this range. $B$, Schematized ILD tuning curve illustrating the indices used to quantify ILD selectivity. "ILD response modulation" was defined as the difference between a site's largest $(e)$ and smallest $(f)$ response to an ILD value and was expressed as a percentage of the largest response: $(e-f) / e \times 100$. "ILD tuning width" was the range of ILD values that elicited greater than $50 \%$ of the largest response $(g)$. "Best ILD" was the center of this range.

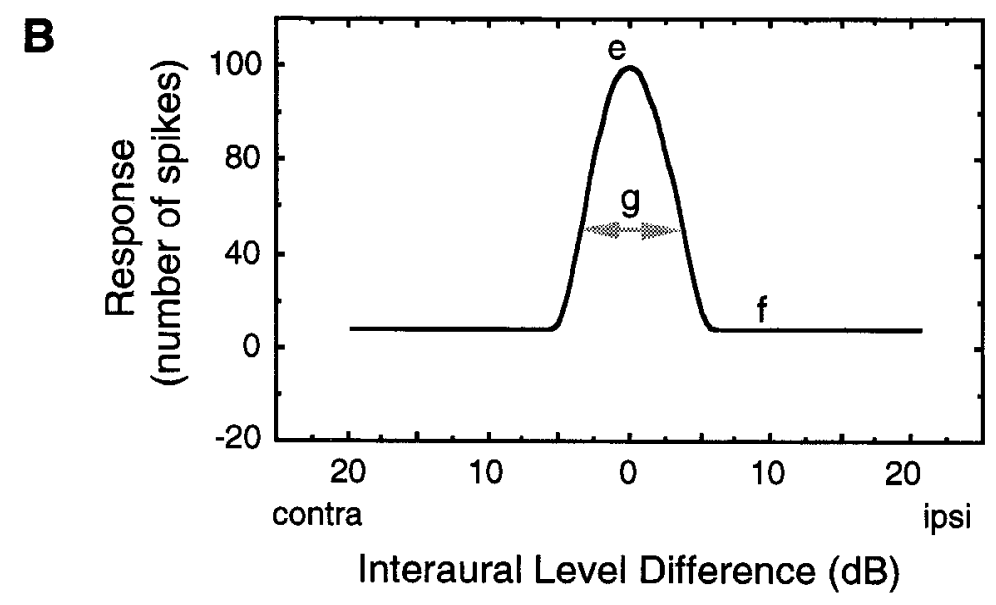

was limited by a site's level of baseline activity: the responses at sites with high levels of baseline activity could be modulated by more than $100 \%$, while responses without any baseline activity were limited to a maximum response modulation value of $100 \%$. To eliminate the effect of differences in baseline activity on response modulation, response modulations that were greater than $100 \%$ were assigned the value of $100 \%$. The second index, "relative size of the secondary peak," was the size of the largest secondary peak relative to the size of the primary peak (c and a, respectively, in Fig. $1 A$ ). If a secondary peak was not apparent, the response to the ITD value that was one period of the site's best frequency away from the ITD that elicited the maximum response was used. The third index, "ITD tuning width," was the continuous range of ITD values that elicited greater than $50 \%$ of the largest response ( $\mathrm{d}$ in Fig. 1A). The center of this range was the site's "best ITD."

ILD selectivity was quantified by measuring "ILD response modulation" and "ILD tuning width" using the dichotic noise stimulus. ILD response modulation was the difference between a site's largest and smallest response (e and $\mathrm{f}$, respectively, in Fig. $1 B$ ), expressed as a percentage of the largest response. ILD tuning width was defined as the continuous range of ILD values that evoked greater than $50 \%$ of the largest response ( $\mathrm{g}$ in Fig. 1B). The center of this range was the site's "best ILD."

"Frequency tuning width" was the continuous range of frequencies that elicited greater than $50 \%$ of the maximum response. The center of this range was the "best frequency."

When ILD tuning was measured, ITD was held constant at the site's best value. Similarly, when ITD tuning was assessed, ILD was held constant at the site's best value. Frequency tuning curves were measured with II'D and ILD at their respective best values.

"Minimum response latency" was based on cumulative histograms representing the combined responses to all stimuli. Latency was the first $1 \mathrm{msec}$ bin in which the responses appeared to increase above baseline.

\section{Analysis of functional organization}

Frequency tuning. Parametric and nonparametric tests were used to examine whether auditory sites are organized into maps of frequency. For the examination of topography along the rostrocaudal and mediolateral axes of the AAr, data were analyzed from all pairs of electrode penetrations, made along either the rostrocaudal or mediolateral axis, that were separated by at least $500 \mu \mathrm{m}$. In each penetration, sites were sampled at a minimum interval of $150 \mu \mathrm{m}$. We searched for evidence of a representation of frequency by comparing the average and median values of best frequency measured in one penetration with the average and median values of best frequency measured in the matched pair. A paired $t$ test was applied to determine whether either the average or median value of best frequency increased along the rostrocaudal or mediolateral axis.

To assess tonotopy along the dorsoventral axis of the AAr, data were analyzed from all electrode penetrations in which measurements were made at two or more sites. We compared neighboring sites (separation $>150 \mu \mathrm{m}$ ) to determine whether the best frequency at a site was greater than the best frequency measured at the adjacent site. A sign-test was then applied to determine whether the proportion of sites with best frequencies that increased along the dorsoventral axis occurred more often than expected by chance.

Tuning for binaural localization cues. We analyzed the functional organization to determine whether best ITDs or best ILDs are organized systematically. For the examination of topography along the rostrocaudal and mediolateral axes of the AAr, data were analyzed from all pairs of electrode penetrations, exactly as described previously for the analysis of frequency tuning organization. In each penetration, sites were 

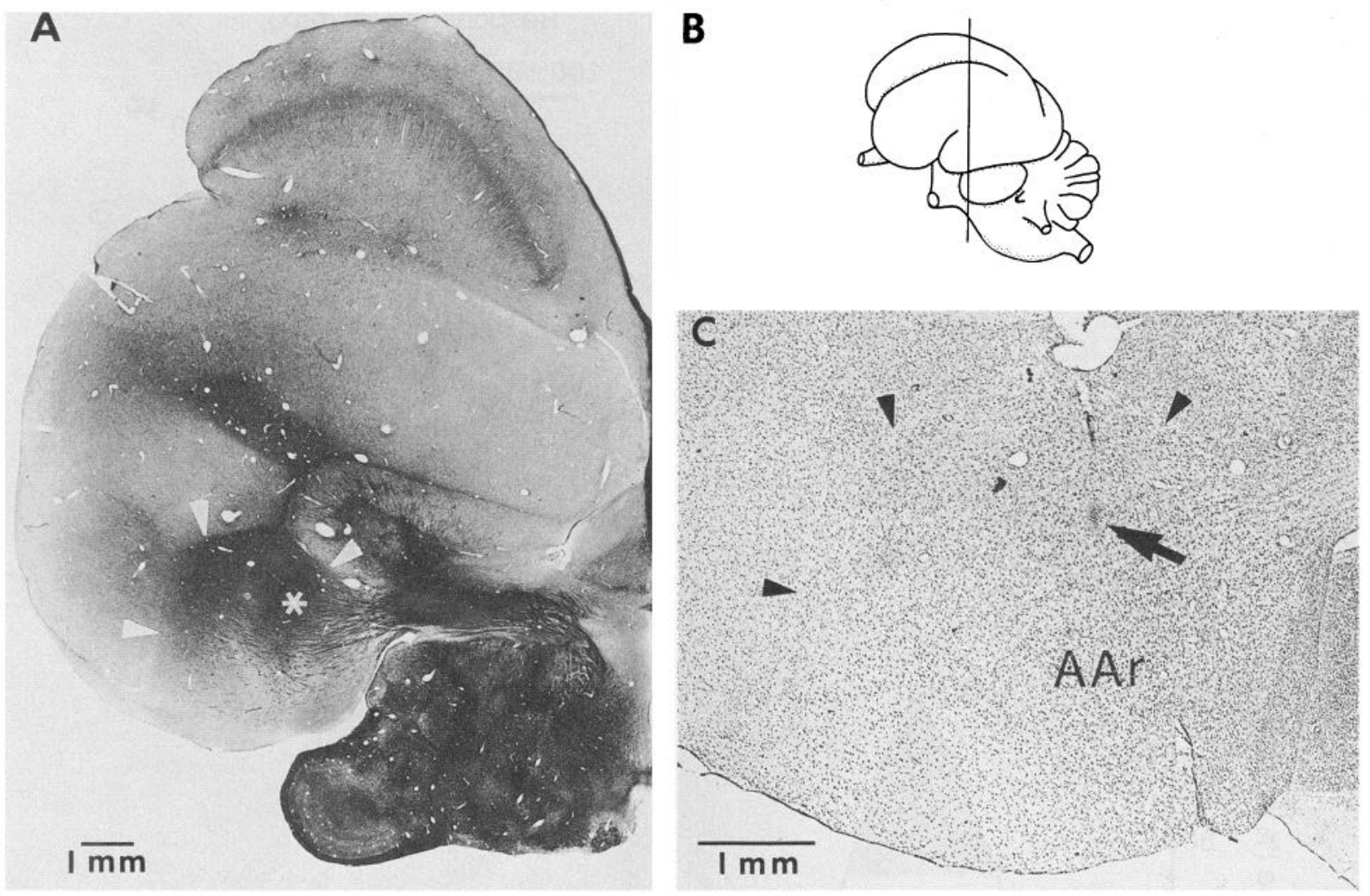

Figure 2. Transverse sections through the auditory archistriatum (AAr). A, A myelin-stained section cut at the level shown in the inset (B). Arrowheads indicate the boundary of the archistriatum. The archistriatum contains two myelin-rich zones. The more medial zone, indicated by the asterisk overlaps with the AAr. $C$, A Nissl-stained section through the AAr. An electrolytic lesion made in the AAr is indicated by the arrow.

sampled at a minimum interval of $150 \mu \mathrm{m}$. We searched for evidence of a systematic representation of ITD by comparing the average and median values of best ITD measured in one penetration with the average and median values of best ITD measured in the matched pair. A paired $t$ test was applied to determine whether either the average or median value of best ITD became more ipsilateral-ear leading along the rostrocaudal or mediolateral axis. The same procedure was followed to determine whether best ILDs became more left-ear greater along either the rostrocaudal or mediolateral axis of the AAr.

For the analysis of topography along the dorsoventral axis of the $\mathrm{AAr}$ data were analyzed from all electrode penetrations in which measurements were made at two or more sites. We compared neighboring sites (separation $>150 \mu \mathrm{m}$ ) to determine whether the best ITD at a site was more ipsilateral-ear leading than the best ITD measured at the adjacent site. A sign-test was then applied to determine whether the proportion of sites that became more ipsilateral-ear leading along the dorsoventral axis occurred more frequently than expected by chance. The same procedure was followed to determine whether best ILDs became more leftear greater along the dorsoventral axis of the AAr.

A Monte Carlo analysis was used to determine whether best ITDs or best ILDs exhibited clustered distributions along the dorsoventral axis. Data were analyzed from all electrode penetrations in which measurements were made at three or more sites and in which adjacent sites were separated by at least $150 \mu \mathrm{m}$. For each pair of adjacent sites in a given electrode penetration, the difference between best ITD values was determined, and the average difference for all such pairs of sites, the "experimental mean," was calculated for that penetration. Next, the distribution of average differences that would result from random combinations of best ITD values for a similar number of recording sites was calculated. This distribution was determined from 1000 Monte Carlo simulations which randomly selected $n$ best ITD values from the pool of best ITD values measured in that animal, where $n$ equals the number of sites in the penetration being tested. The "simulation mean" was the average value from this distribution. The experimental mean was then compared to the simulation mean. Those penetrations with experimental means that were smaller than the simulation mean were termed "clustered," and those with experimental means that were larger were termed "not clustered." A sign-test was then applied to determine whether the proportion of electrode penetrations with clustered best ITDs occurred more frequently than expected by chance. The same procedure was followed to determine whether best ILDs were clustered along the dorsoventral axis.

Histology. Recording sites were verified histologically. In the final experiment in each owl, electrolytic lesions $(3.0 \mu \mathrm{A}$ for $15 \mathrm{sec})$ were placed or biotinylated dextran amine was pressure injected in the region containing auditory units. After a few days of survival, the owl was deeply anesthetized with sodium pentobarbital and perfused intracardially with $4 \%$ paraformaldehyde and $5 \%$ sucrose in $0.1 \mathrm{~m}$ phosphate buffer. The brains were blocked in the transverse plane, cut on a freezing microtome in $40 \mu \mathrm{m}$ sections, mounted on glass slides, and stained with cresyl violet or with a myelin (modified Gallyas) stain. The dextran amine was visualized with an avidin-biotinylated HRP (ABC) procedure followed by a standard diaminobenzidine reaction (some of the results of these tracer injections can be found in the companion article, Knudsen et al., 1995). Recording sites were reconstructed using a camera lucida.

\section{Results}

\section{Location of the auditory region of the archistriatum}

The archistriatum is separated from the neostriatum and paleostriatum by a thin cell-free zone (arrowheads in Fig. 2). The medial posterior third of the archistriatum is believed to be analogous to the mammalian amygdala while the anterior two-thirds of the archistriatum is considered analogous to mammalian sensorimotor cortex (Zeier and Karten, 1971). In the barn owl, the archistriatum extends approximately $4.0 \mathrm{~mm}$ rostrocaudally, from the level of the optic chiasm to the level of the nuclei 

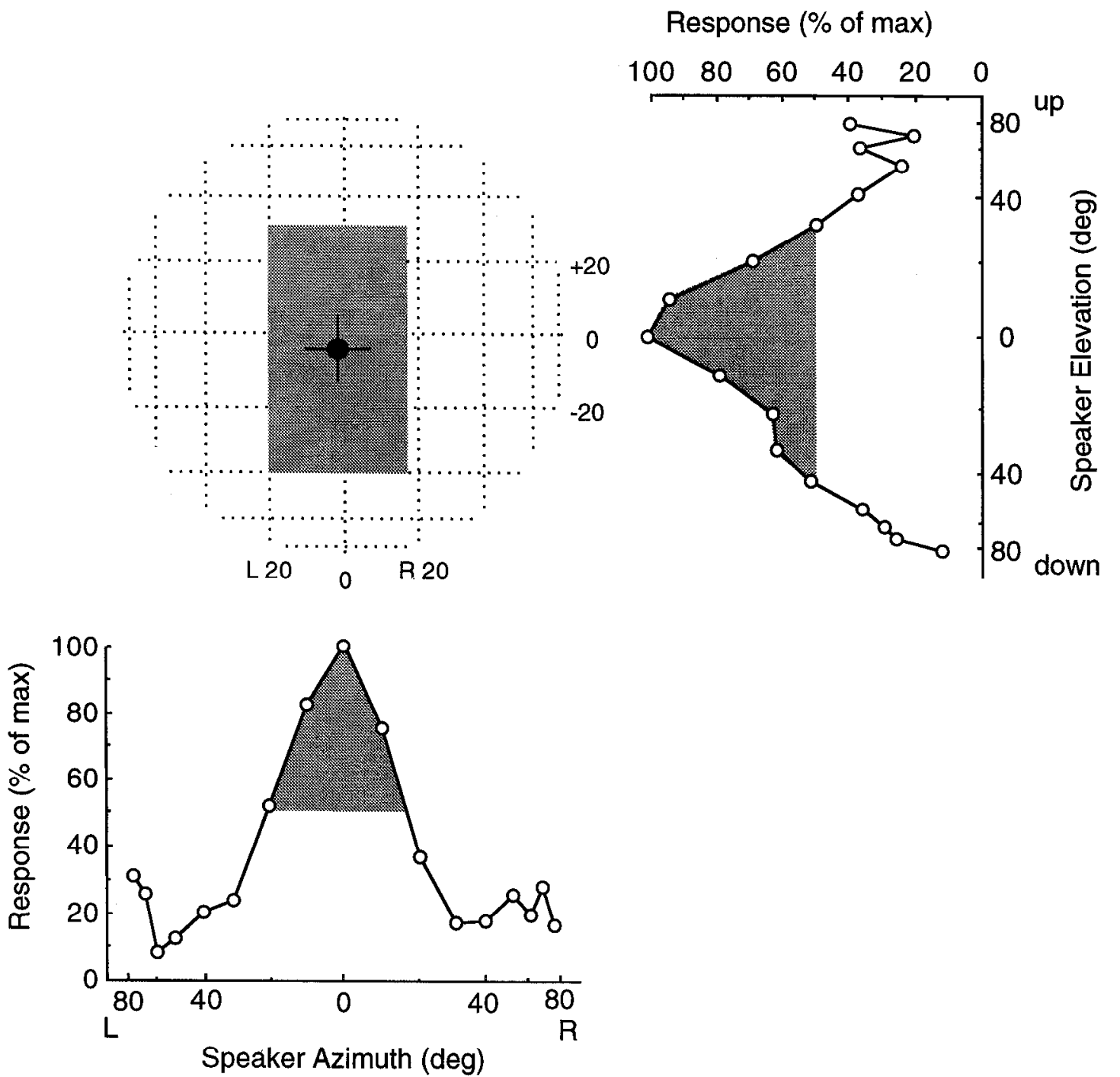

Figure 3. Free-field spatial tuning of an AAr site. The dashed globe represents the frontal hemifield and is calibrated in $20^{\circ}$ intervals of azimuth and elevation. The shaded square on the globe represents the best area of the site. The cross is placed at the geometric center of the site's best area which defines the site's best azimuth and elevation. The effect of varying sound source azimuth and elevation on the site's response is shown below and to the right. Tuning to source azimuth was measured with the sound source at the site's best elevation; tuning to source elevation was measured with the sound source at the site's best azimuth. The shaded regions of the azimuth and elevation tuning curves represent the spatial locations that elicited greater than $50 \%$ of the maximum response.

Figure 4. Correspondence between predicted and measured best ITD and best ILD. A: Left, Azimuthal tuning of two AAr sites. The shaded region on each curve represents the azimuthal locations of the sounds that elicited greater than $50 \%$ of the maximum response. The center of this region, the best azimuth, is indicated by the open triangle. Middle, The spatial pattern of ITD for frequencies near the best frequencies of the sites. The contour lines on the globe indicate how ITD varies across the frontal hemifield for the $1 / 3$-octave interval centered near $7 \mathrm{kHz}$. The plot represents data averaged over the frequency range of $6.3-8.0 \mathrm{kHz}$ measured every $10^{\circ}$ in azimuth and elevation from five normal owls. The contour lines represent iso-ITD ${ }_{7 \mathrm{kHz}}$ lines in increments of $25 \mu \mathrm{sec}$. Solid lines indicale rightl-ear leading; broken lines indicate left-ear leading. The shaded line indicates ITD $=0 \mu \mathrm{sec}$. The position of the open triangle on each globe indicates the location of the center of the best areas of those sites shown on the left. The best azimuth of each site was determined from its azimuth (shown on the left) and elevation (data not shown) tuning. The acoustic ITD that is produced by a sound source located at this spatial location was the site's "predicted best ITD." Right, ITD tuning. ITI) tuning was measured at the same sites. The shaded region on each ITD tuning curve defines the tuning width of each site, the center of which is the site's best ITD. The solid triangle indicates the best ITD of each site while the open triangle indicates the site's predicted best ITD. B: Left, Elevation tuning of two AAr sites. The shaded region on each curve represents the elevations of the sounds that elicited greater than $50 \%$ of the maximum response. The center of this region, the best elevation, is indicated by the open triangle. Middle. The spatial pattern of ILD for frequencies near the best frequencies of the sites. The contour lines on the glohe indicate how II D varies across the frontal hemifield for the $1 / 3$-octave interval centered near $7 \mathrm{kHz}$. The plot represents data averaged over the frequency range of $6.3-8.0 \mathrm{kHz}$ measured every $10^{\circ}$ in azimuth and elevation from five normal owls. The contour lines represent iso-ILD ${ }_{7 \mathrm{kz}}$ lines in increments of $3 \mathrm{~dB}$. Solid lines indicate right-ear greater; broken lines indicate left-ear greater. The shaded line indicates ILD $=0$ $\mathrm{dB}$. The position of the open triangle on each globe indicates the location of the center of the best areas of those sites shown on the left. The best elevation of each site was determined from its azimuth (data not shown) and elevation (as shown on the left) tuning. The acoustic ILD that is produced by a sound source located at this spatial location was the site's "predicted best ILD." Right, ILD tuning. ILD tuning was measured at the same sites. The shaded region on each ILD tunimg curve defines the tuning width of each site, the center of which is the site's best ILD. The solid triangle indicates the best ILD of each site while the open triangle indicates the site's predicted best ILD. 
A

Azimuthal Tuning
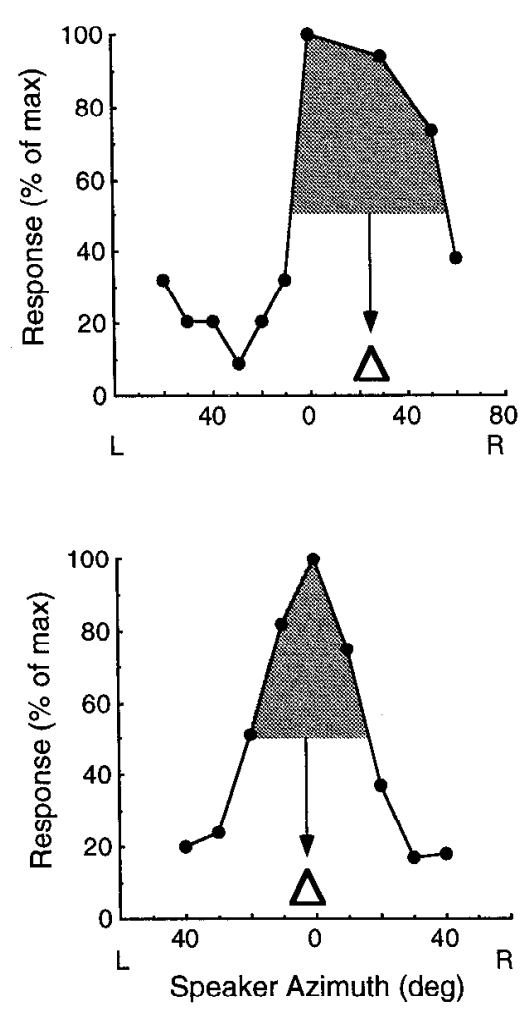

B

Elevational Tuning
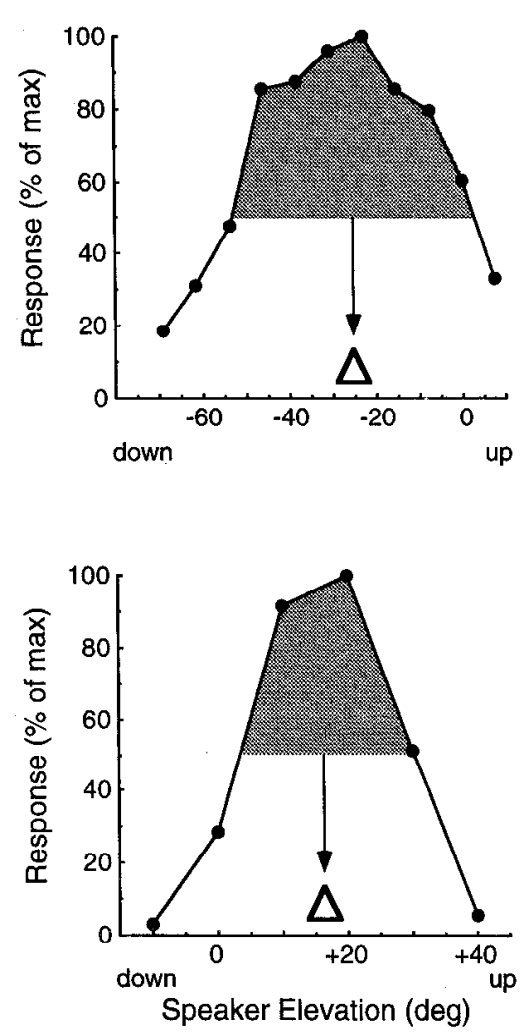

Acoustic Pattern of ITD
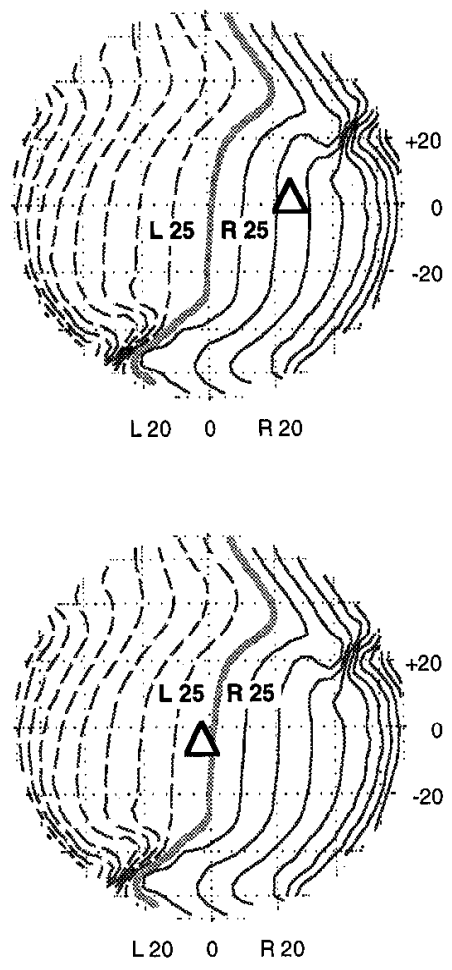

Acoustic Pattern of ILD
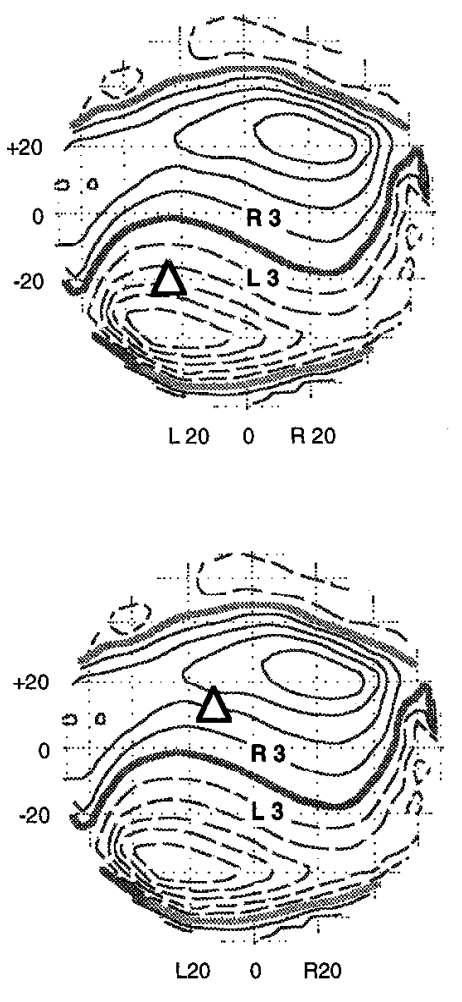

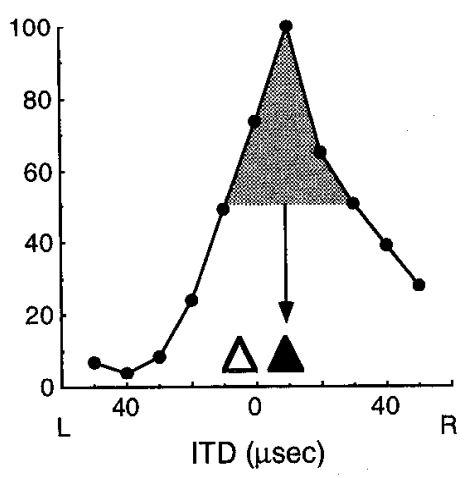

ITD Tuning

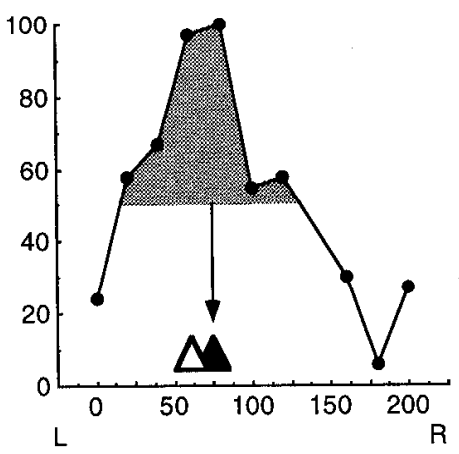

ILD Tuning
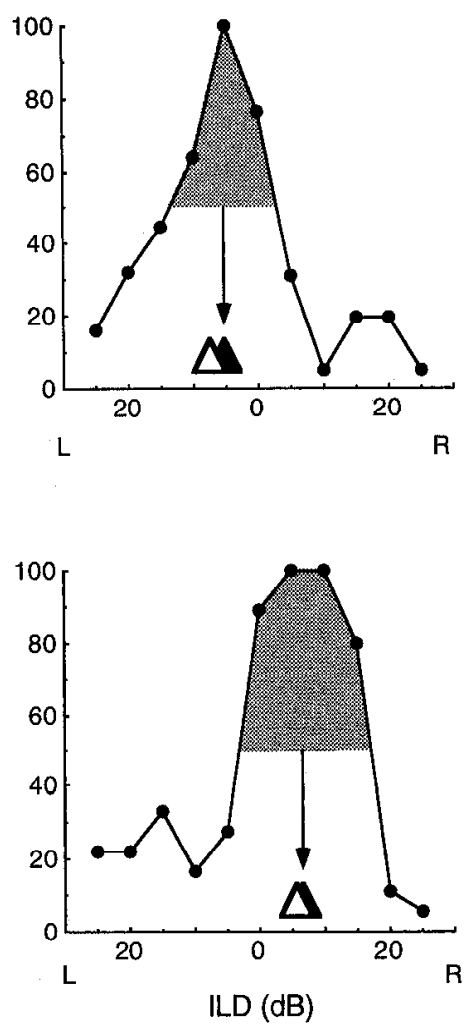
rotundus and ovoidalis. The auditory region of the archistriatum, the AAr, is small $\left(\approx 1.0 \mathrm{~mm}^{3}\right)$ and is located approximately halfway along the rostrocaudal extent of the structure, at the level of the anterior commissure. It is contained within the AGF which, based on gaze changes elicited by microstimulation, occupies the anterior $70 \%$ of the archistriatum. When viewed in the transverse plane, the archistriatum contains two myelin-rich zones; the auditory region overlaps with the more medial zone (the asterisk in Fig. $2 A$ ).

\section{Spatial receptive fields}

Spatial tuning was measured at 13 multiunit sites in both hemispheres of two barn owls. At each site, responses varied greatly as a function of sound source location (Fig. 3). The strongest responses were evoked when the sound source was located within a particular area of space, the site's best area. However, while spatially tuned, many of the sites responded to sounds originating from nearly any location.

The sharpness of spatial tuning was quantified by the size of the best area, defined as the region of space from which noise bursts evoked more than $50 \%$ of the maximum response. The azimuthal extent of best areas was always clearly defined and averaged $33^{\circ}(\mathrm{SD}=15.7)$. The elevational extent was well defined at most but not at all sites: at three sites, responses did not fall below the $50 \%$ criterion as a function of source elevation and elevation tuning at these sites was classified as undefined. For the remainder of the sites, best areas averaged $46^{\circ}$ (SD $=$ 13.8 ) in elevation.

\section{Relationship between spatial and binaural tuning}

The majority of the data collected in this study were dichotic measurements of unit tuning to binaural localization cues. To determine whether a consistent relationship exists between freefield measurements of spatial tuning and dichotic measurements of binaural tuning, we measured both spatial and binaural tuning at 13 sites. The location in space to which a site was tuned was represented by the geometric center of the site's best area. The ITD and ILD tuning predicted by this location were derived from acoustic measurements of ITD and ILD that were made in five normal owls (Knudsen et al., 1991). "Predicted best ITD" and "predicted best ILD" were the acoustic ITD and ILD, respectively, produced by a sound source located at the center of the best area, for the $1 / 3$ octave bandwidth centered on the site's best frequency. Predicted best ITDs and best ILDs were then compared with dichotically measured best ITDs and best ILDs for the same sites.

Predicted best ITDs corresponded closely with measured best ITDs (Fig. 4A). The average difference between the predicted and measured values was $13 \mu \mathrm{sec}$ ( $\mathrm{SD}=11.1$ ), which corresponds to an average spatial discrepancy of about $5^{\circ}$ azimuth (Knudsen et al., 1994). Similarly, for those sites with well-defined elevational tuning, predicted best ILDs matched well with measured best ILDs (Fig. 4B). The average difference between the predicted and measured values was $4 \mathrm{~dB}(\mathrm{SD}=3.3)$. In the frontal region of space (within $20^{\circ}$ of the visual axes), this ILD difference corresponds to an average spatial discrepancy of about $8^{\circ}$ elevation for frequencies from 6 to $8 \mathrm{kHz}$ (Knudsen et al., 1994). Thus, dichotically measured best ITD and best ILD are reliable indicators of best area azimuth and best area elevation, respectively, in the AAr.

\section{Responses to dichotic stimuli}

Responses to dichotic stimulation were assessed at 135 AAr sites from both hemispheres of seven barn owls. Differences in the sample sizes for our different analyses occurred because occasionally units were lost before a complete set of tuning curves could be obtained.

Frequency tuning. A substantial percentage $(28 \%, 36 / 127)$ of $\mathrm{AAr}$ sites were unresponsive to tonal stimuli, regardless of sound level. For sites at which frequency tuning could be quantified $(72 \%, 91 / 127)$, frequency tuning was broad (Fig. 5A,B), averaging $3.0 \mathrm{kHz}(\mathrm{SD}=1.1$; range $=1.0-6.0 \mathrm{kHz})$ at halfmaximum response. Quality factors, calculated by dividing the best frequency by the $50 \%$ tuning width, also indicated that frequency tuning was broad (average 2.4 ; $\mathrm{SD}=1.1$ ). Best frequencies ranged from 3.0 to $8.0 \mathrm{kHz}$ with a mean best frequency of $6.3 \mathrm{kHz}(\mathrm{SD}=1.0$; Fig. $5 C$ ). The majority of sites $(91 \%, 82 / 91)$ had best frequencies between 5 and $8 \mathrm{kHz}$, which is at the upper end of the owl's audible range.

ITD tuning. Responses at all sites in the AAr were affected by ITD. Typically, ITD tuning curves exhibited a large "primary" peak and smaller, "secondary" peaks at ITDs ipsilateral and/or contralateral to the primary peak (Fig. 6A-C). At some sites, strong responses were restricted to a single, small range of ITD values (Fig. 6A). At others, secondary peaks could be large (Fig. 6B,C) and/or responses could be elicited across the entire physiological range of ITDs (Fig. 6C). Finally, some sites did not appear to have closed ITD tuning: these sites were sensitive to contralateral-ear leading ITDs (Fig. 6D).

The degree to which ITD tuning curves were selective for specific values of ITD was assessed using the three indices defined in Figure $1 A$ (see Materials and Methods). In this figure and in the remaining figures, "response" was defined as the number of spikes elicited after subtracting baseline activity. ITD response modulation ranged from 44 to $100 \%$ with a median value of $100 \%$ (Fig. $7 A$ ). At $45 \%$ of the sites, ITD response modulation was below $100 \%$, indicating that these sites could respond, to some degree, to any ITD within the physiological range of ITDs $( \pm 200 \mu \mathrm{sec})$. Secondary peaks tended to be small relative to the primary peaks (Fig. $7 B$ ): on average, the responsc at the sccondary pcak was approximately half as large $($ mean $=55 \%, \mathrm{SD}=27$ ) as the response at the primary peak.

The width of the primary peak could be measured for the majority $(89 \%, 113 / 127)$ of AAr sites (Fig. $8 B$ ). The width of the primary ITD peak averaged $65 \mu \mathrm{sec}$ ( $\mathrm{SD}=23$; range $=$ 21-146 $\mu \mathrm{sec})$. For the remaining sites, ITD tuning widths could not be measured because responses to the largest contralateral-ear leading ITD values did not fall below $50 \%$ of the maximum response over the physiological range of ITDs (e.g., Fig. 6D).

Best ITDs were calculated for 113 sites (Fig. $8 C$ ). While the range of best ITDs (contralateral $158 \mu \mathrm{sec}$ to ipsilateral 213 $\mu \mathrm{sec}$ ) nearly covered the physiological range of ITDs, the vast majority $(81 \%, 91 / 113)$ of sites were tuned to contralateral-ear leading ITDs. In addition, a substantial proportion $(68 \% ; 77 /$ 113) were luned to ITD values of less than $50 \mu \mathrm{sec}$ ITD, corresponding to sound sources located within the frontal $40^{\circ}$ of space (Fig. 4A).

ILD tuning. Nearly all $(93 \%, 125 / 135)$ of the sites were tuned for specific values of ILD (Fig. 9A). A minority $(7 \%, 10 / 135)$ were not tuned and, instead, were sensitive to contralateral-ear 

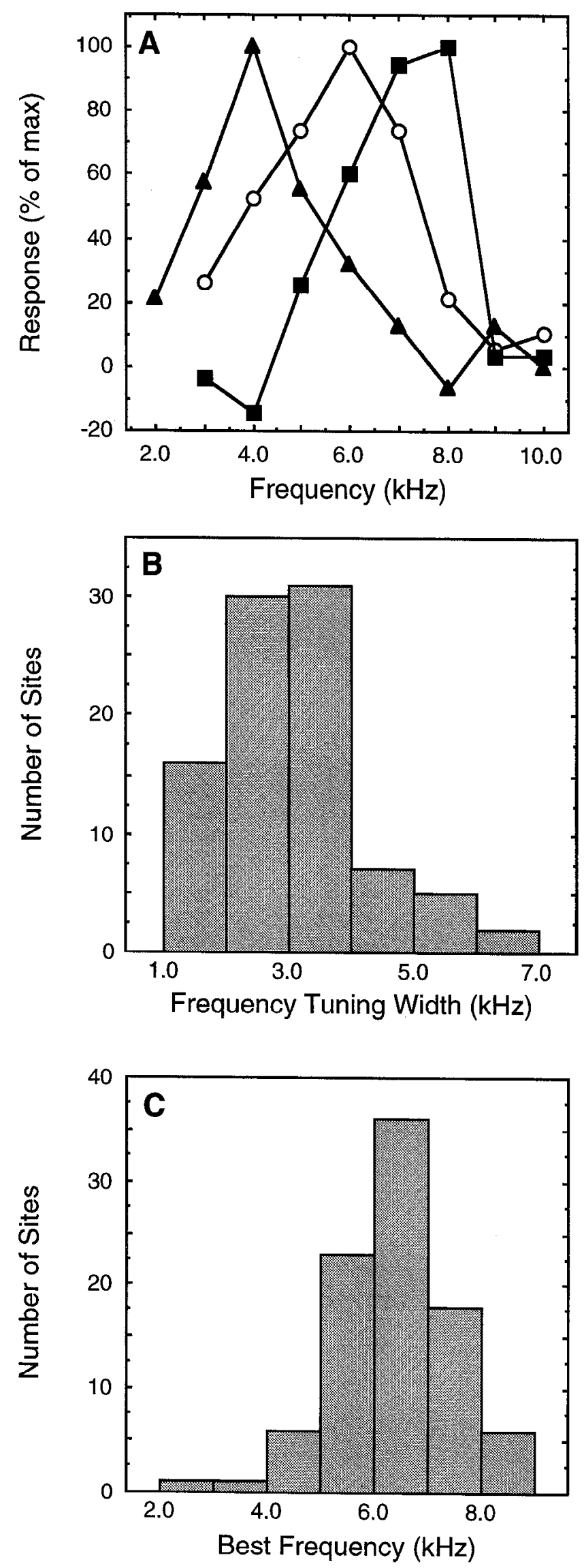

Figure 5. Frequency tuning of AAr sites. A, Examples of frequency tuning curves. Negative response values indicate responses that were greater ILDs (Fig. 9B). For these sites, ILD tuning widths could not be calculated because responses did not fall below $50 \%$ of the maximum response at the largest value of contralateral-ear greater ILD. The degree to which ILD tuning curves were selective for specific values of ILD was assessed using the two indices defined in Figure $1 B$ (see Materials and Methods). ILD response modulation ranged from 54 to $100 \%$ with a median value of $96 \%$ (Fig. $10 A$ ). Over half $(61 \%)$ of the sites had ILD response modulation values of less than $100 \%$, indicating that the majority of sites responded, to some degree, to any ILD within the physiological range of ILDs $( \pm 20 \mathrm{~dB})$. For sites that were tuned for ILD, the average $I L D$ tuning width was $27 \mathrm{~dB}$ $(\mathrm{SD}=11$; range $=7-60 \mathrm{~dB} ;$ Fig. $10 B)$.

Best ILDs ranged from $22 \mathrm{~dB}$ contralateral-ear greater to 20 dB ipsilateral-ear greater (Fig. 10C) which corresponds well with the range of ILD values that the auditory system normally experiences (see Brainard et al., 1992; Knudsen et al., 1994).

\section{Influence of sound level on dichotic tuning}

Neurons in the owl's OT have level-independent binaural tuning (Olsen et al., 1989). To test whether this is also true in the AAr, we assessed the effect of sound level on binaural tuning to stimuli at 20 and at $40 \mathrm{~dB}$ above threshold for 14 single unit and 11 multiunit sites (Fig. 11). Increasing sound level increased the width of ITD tuning curves by a small, but significant, amount $(9 \mu \mathrm{sec} ; t=1.9, \mathrm{df}=25, p<0.05)$ while having no systematic effect on best ITD (paired $t$ test, $t=1.9$, df $=25, p>0.05$; Fig. $11 B$ ). Sound level had no significant effect on either ILD tuning width $(t=1.9, \mathrm{df}=25, p>0.05)$ or best ILD (paired $t$ test, $t=0.95$, df $=25, p>0.05$; Fig. $11 D$ ). Thus, the binaural tuning of units in the AAr was essentially insensitive to overall sound level.

\section{Response latency}

The distribution of minimum response latencies is presented in Figure 12. The median latency for AAr sites was $25 \mathrm{msec}(n=$ 135) with $93 \%$ of sites having latencies of less than $37 \mathrm{msec}$. The shortest latency observed was $14 \mathrm{msec}$ while the longest was $51 \mathrm{msec}$.

\section{Functional organization}

Frequency organization. There was no evidence of a systematic change in best frequency along any dimension of the $\operatorname{AAr}(p>$ $0.05)$.

Organization of binaural localization cues. We found no evidence of an organization, based on binaural tuning, that would be consistent with the existence of a single, continuous map of auditory space in the AAr (Fig. 13). Best ITDs and best ILDs did not change systematically along either the rostrocaudal, mediolateral, or dorsoventral axes $(p>0.05)$.

While there was no global map of binaural cue values, best ITDs and best ILDs did tend to cluster. Best ITDs either changed gradually or remained constant along dorsoventral electrode penetrations. Examples of data from dorsoventral electrode penetrations, together with their Monte Carlo analyses for clustering (see Materials and Methods), are shown in Figure 14. In the penetration shown in Figure 14A, best ITDs progressed smoothly with one, and perhaps two, reversals in the progression of $\leftarrow$

below baseline activity. $B$, Distribution of frequency tuning widths. $C$, Distribution of best frequencies. 
Figure 6. Examples of ITD tuning curves. $A C$, Examples of ITD tuning curves with primary and secondary peaks. $D$, An AAr site that was sensitive to contralateral-ear leading ITDs.
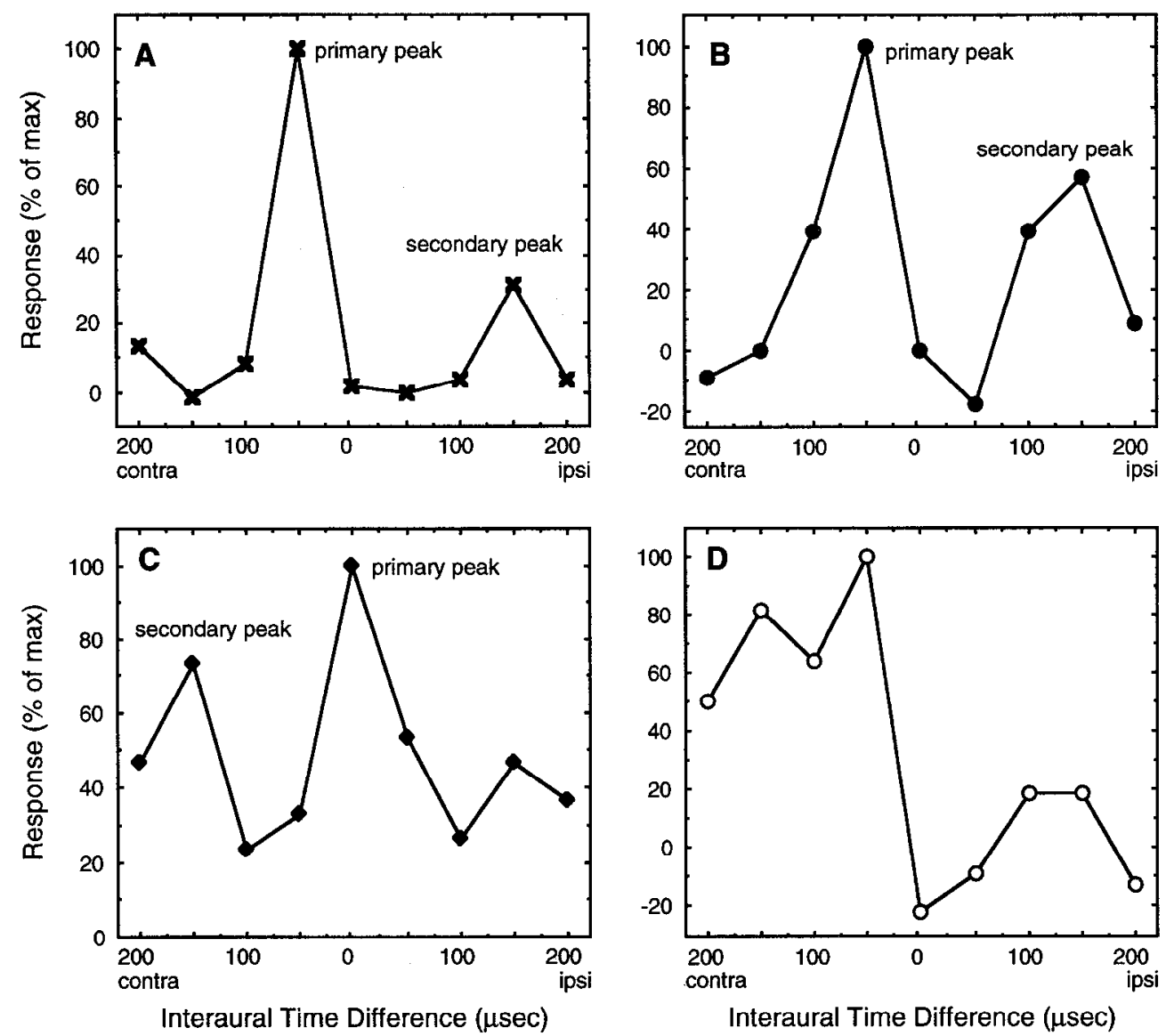

values. The average nearest-neighbor difference for this penetration was $31 \mu \mathrm{sec}$ which was in the 10 th percentile of the Monte Carlo distribution, indicating more clustering of best ITDs than would be expected by chance. The data shown in Figure $14 B$ are from a penetration in which best ITDs were essentially constant along the dorsoventral electrode penetration. In this case, the average nearest-neighbor difference for the penetration was $15 \mu \mathrm{sec}$ which was in the eleventh percentile of the Monte Carlo distribution, again indicating more clustering of best ITD values than would be expected by chance. Of the 20 penetrations in which we were able to measure best ITDs at three or more sites, $16(80 \%)$ exhibited clustering. This is a significantly greater number than would have been expected to show clustering by chance $(z=2.68, p<0.004)$.

Similarly, best ILDs were clustered in the dorsoventral dimension of the AAr (Fig. 15). Figure 15A shows data from a penetration in which best ILDs clustered near one value and then changed abruptly to another value. Figure $15 B$ shows an example of a penetration in which best ILDs remained essentially constant throughout the dorsoventral extent of the AAr. For both of these penetrations, the average difference between best ILDs measured at neighboring sites was less than the value expected based on chance, according to their respective Monte Carlo simulations. Sixteen $(73 \%)$ of the 22 penetrations showed similar clustering of best ILDs. This is a significantly greater number of penetrations than would have been expected to show clustering by chance $(z=1.79, p<0.036)$.

\section{Discussion}

We have identified an auditory region in the barn owl archistriatum, the AAr, which contains neurons that are spatially tuned and are highly selective for binaural localization cues. AAr sites tend to be broadly tuned for sound frequency, they are all sensitive to both the ITD and the ILD of a stimulus, and nearly all $(86 \%)$ are tuned sharply for both ITD and ILD. The tuning of AAr units for particular values of ITD and ILD exhibits a local organization, instead of a global, topographic one.

High concentrations of units with comparable spatial and binaural tuning properties have been observed in regions of the brain that are known to contribute to spatial behaviors (Sprague and Meikle, 1965; Schneider, 1969; Casagrande and Diamond, 1974; Knudsen, 1982; Jay and Sparks, 1984; Stein et al., 1989; Knudsen et al., 1993; Wagner, 1993). For example, in owls and in various mammalian species, both the ICX and the OT contain such populations of functionally specialized auditory units (Moiseff and Konishi, 1981a; Wise and Irvine, 1983, 1984, 1985; Hirsch et al., 1985; Middlebrooks, 1987; Olsen et al., 1989; Binns et al., 1992; Mogdans and Knudsen, 1993). Units with similar spatial and binaural properties have also been observed in the owl's basal ganglia (Cohen and Knudsen, 1994). Although the role of the basal ganglia in owls has not been demonstrated, the basal ganglia have been shown to contribute to high-order spatial behaviors in a variety of avian and mammalian species (Potcgal, 1969, 1971; Wesp and Goodman, 1978; Bugbee, 1979; Goodman et al., 1982; Rieke, 1980, 1981, 1982; Sanberg and Mark, 1983; Cook and Kesner, 1988; Kennard and I lleck, 1989; Packard et al., 1989; Hikosaka, 1991). The discovery that the barn owl AAr contains a high concentration of functionally specialized units similar to those in the ICX, OT, and basal ganglia suggests that the AAr contributes to the forebrain control of spatial behaviors requiring the localization of auditory stimuli. 

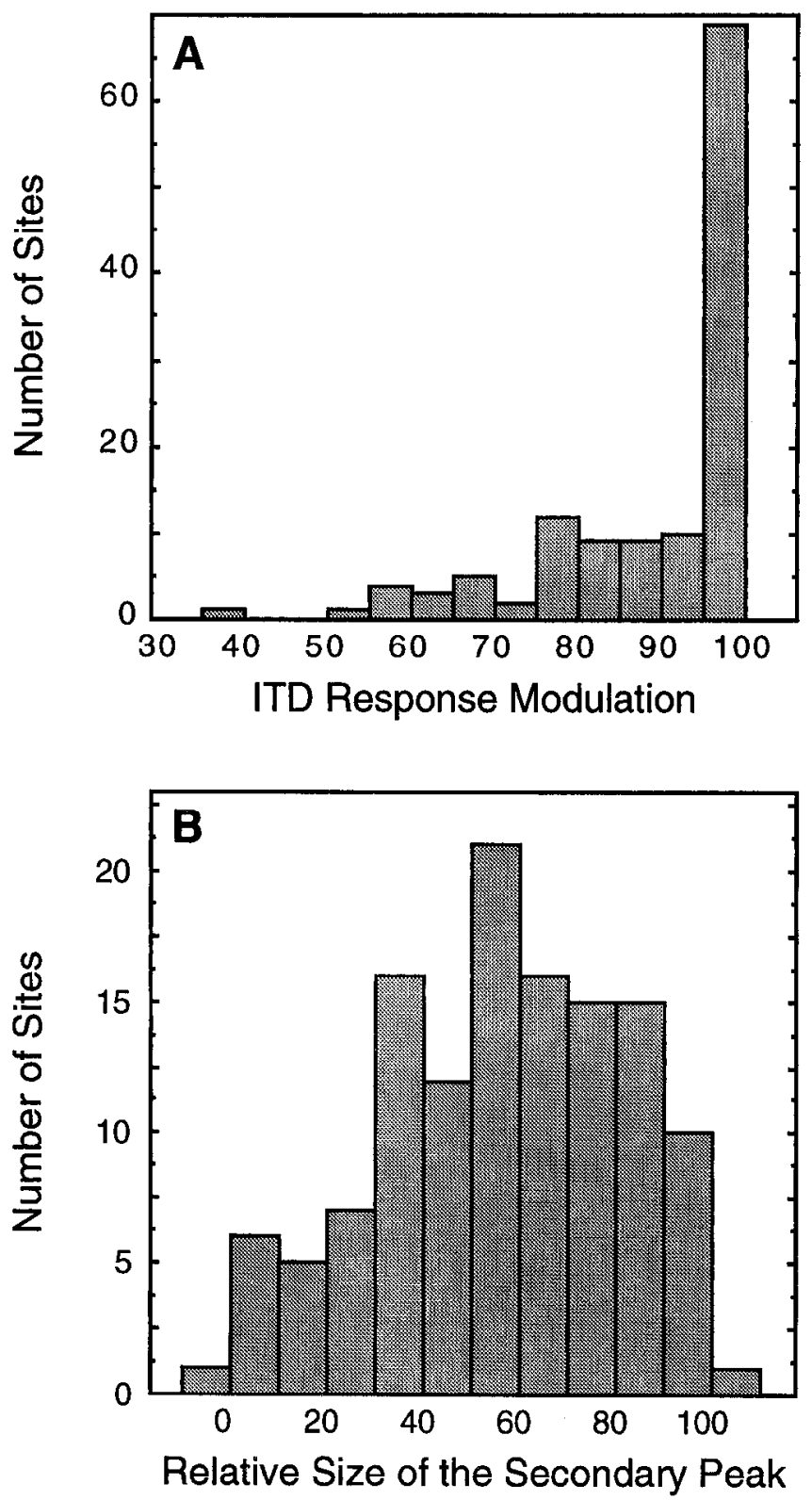

Figure 7. Distributions of ITD selectivity. $A$, ITD response modulation is the difference between a site's largest and smallest response to an ITD value and expressed as a percentage of the largest response as defined in Figure 1. B, Relative size of the secondary peak is the response at the largest secondary peak in the ITD tuning curve expressed as a percentage of response at the primary peak as defined in Figure 1.

In the discussion that follows, we compare the functional properties of AAr units with those of auditory units in other regions of the owl's brain. We describe the marked differences hetween the forebrain and midbrain representations of auditory space and speculate as to why a single, continuous map of auditory space, though present in the midbrain, may not exist in the forebrain.

\section{Comparison with other auditory regions in the owl}

The properties of AAr units are unlike those of units in the primary central auditory pathway (for a review, see Clarey et al., 1992). Most units in this pathway are tuned sharply for frequency and are organized according to their frequency tuning into tonotopic maps. Many are also sensitive to ILD and/or to
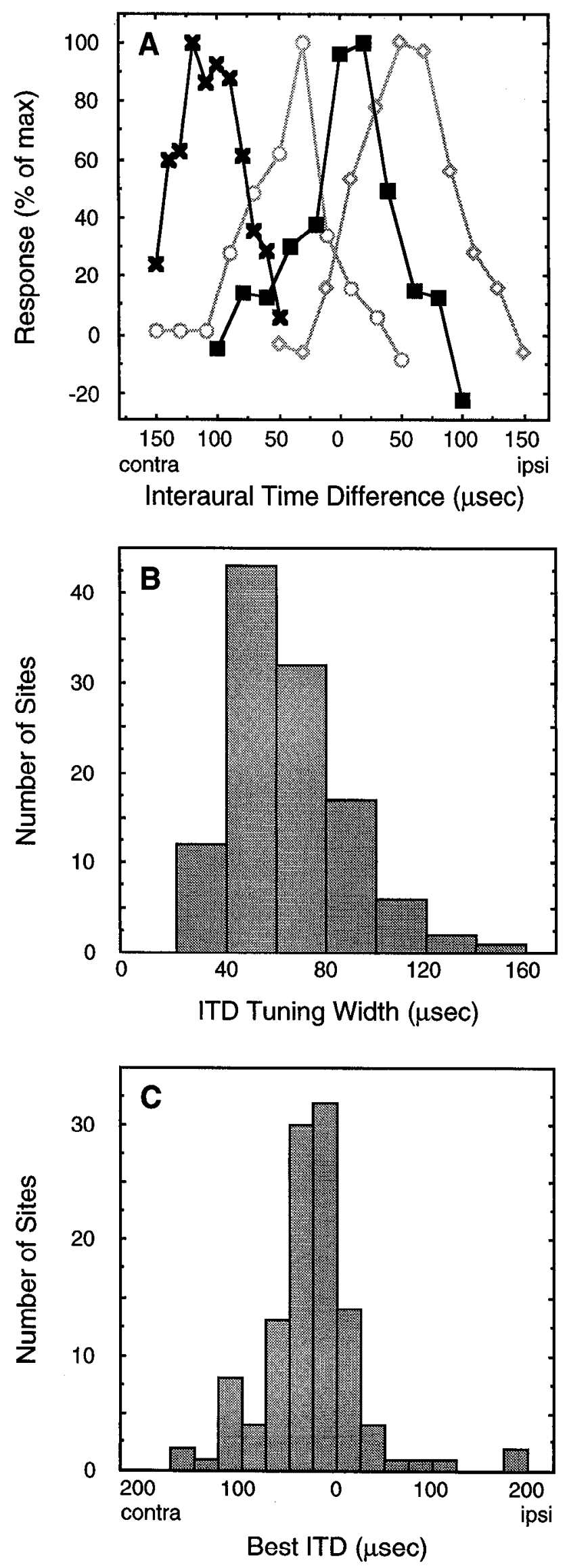

Figure 8. ITD tuning. A, Representative primary peak ITD tuning curves. $B$, Distribution of ITD tuning widths (d in Fig. 1). $C$, Distribution of best ITDs. 

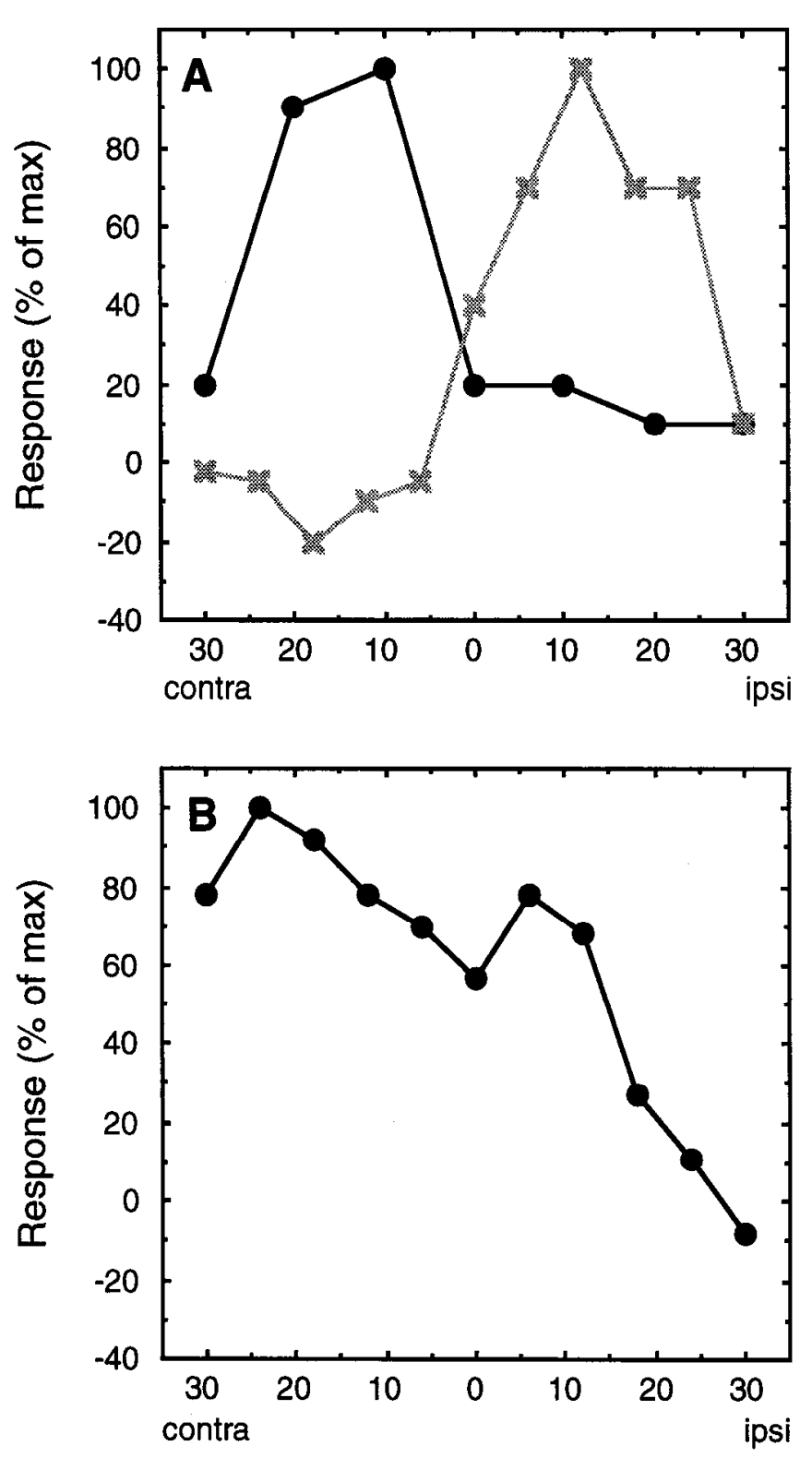

Interaural Level Difference (dB)

Figure 9. Examples of ILD tuning. A, Two AAr sites tuned for specific values of ILD. $B$, An AAr site is sensitive to contralateral-ear greater ILDs.

interaural phase difference (IPD). Because such units respond to only a narrow range of frequencies, their tuning to the ITD of a broad band stimulus is a periodic function, reflecting the unit's sensitivity to the IPD of its best frequency within the broad band sound. The spatial receptive fields of these units consist of large and often multiple discrete regions of space corresponding to the phase ambiguity of the IPD cue as well as to the spatial ambiguities that are inherent to ITD and ILD cues (see Brugge et al,, 1969; Yin and Kuwada, 1984; Irvine, 1986; Carr and Konishi, 1988; Fujita and Konishi, 1991; Brainard et al., 1992).

Figure 10. ILD tuning. A, Distribution of "ILD response modulation." ILD response modulation is the difference between a site's largest and smallest response to an ILD value and expressed as a percentage
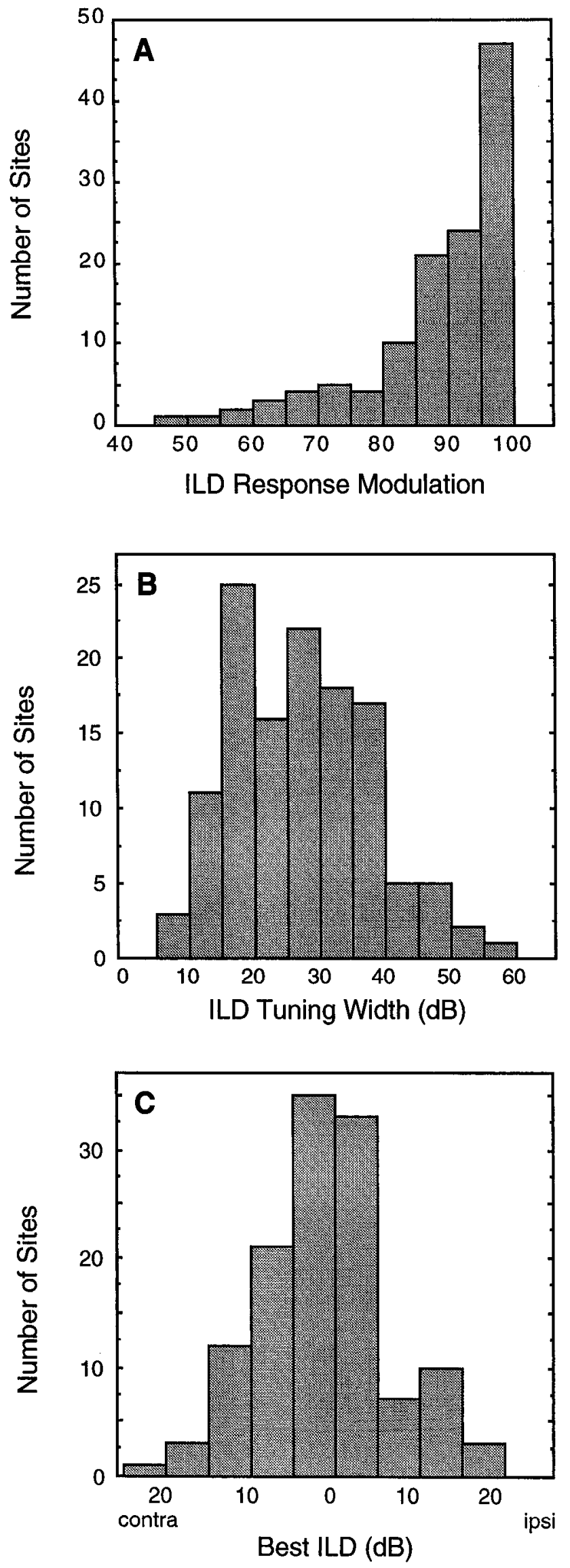

of the largest response. $B$, Distribution of ILD tuning widths. $C$, Distribution of best ILDs. 

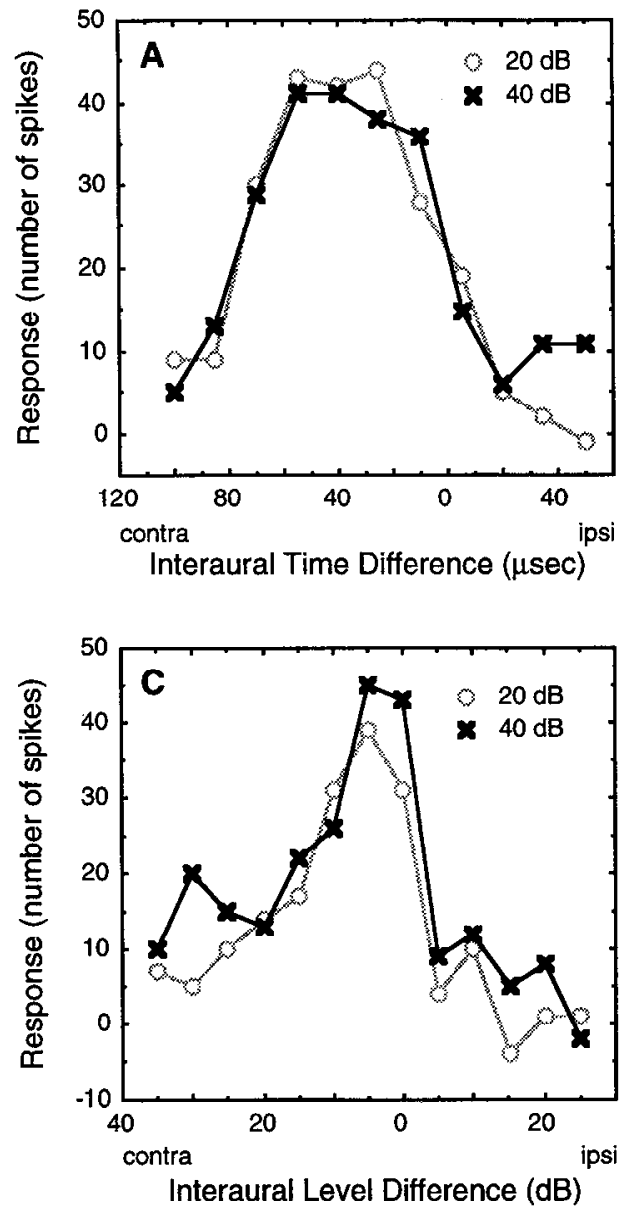

Figure 11. Effect of sound level on ITD and ILD tuning. $A$, An example of ITD tuning mcasured at 20 and $40 \mathrm{~dB}$ above threshold; as at most sites, ITD tuning was relatively insensitive to sound level. $B$, Summary of the effect of ABL on the best ITDs of AAr sites. Best ITDs at $20 \mathrm{~dB}$ above threshold are plotted versus best ITDs at $40 \mathrm{~dB}$ above threshold. The diagonal line represents no change in best ITD with sound level. $C$, An example of ILD tuning measured at 20 and $40 \mathrm{~dB}$ above threshold; as at most sites, ILD tuning was relatively insensitive to sound level. $D$, Summary of the effect of ABL on the best ILDs of AAr sites. Best ILDs at $20 \mathrm{~dB}$ above threshold are plotted versus best ILDs at $40 \mathrm{~dB}$ above threshold. The diagonal line represents no change in best ILD with sound level.
The functional properties of AAr units represent a higher level of space processing. By integrating IPD and ILD information across frequency, they eliminate much of the spatial ambiguity that is associated with any single, frequency-specific cue (Takahashi and Konishi, 1986; Olsen et al., 1989; Brainard et al., 1992). The ITD tuning curves of AAr units measured with broad

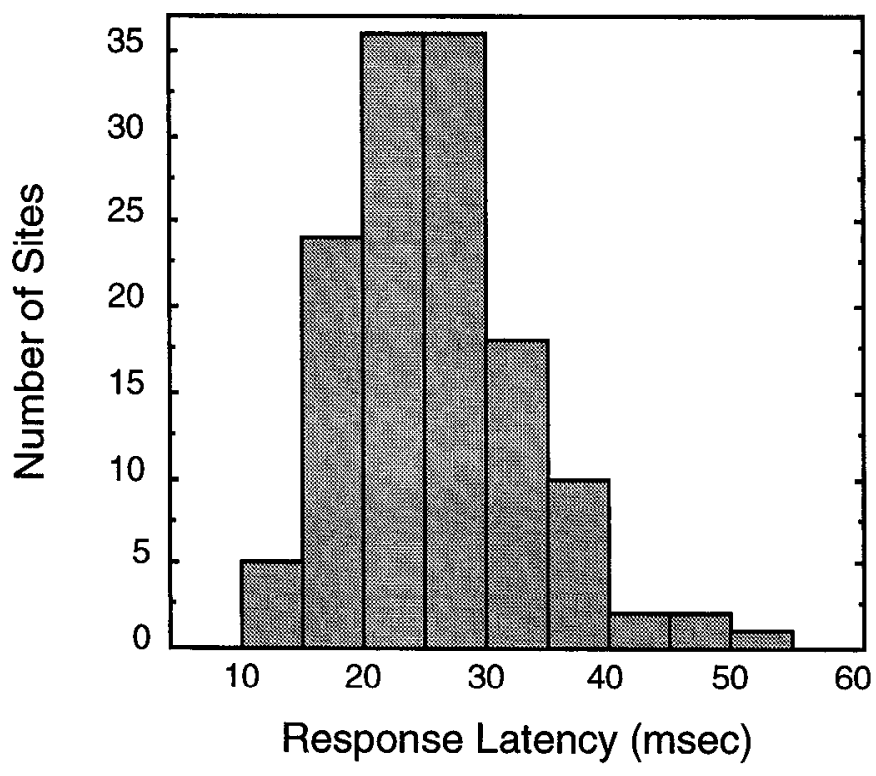

Figure 12. Distribution of minimum response latencies. band sound are not periodic functions. Instead, AAr units respond best to a particular value of ITD, their best ITD. The degree to which the phase ambiguity of the IPD cue is resolved at the level of these units is indicated by the relative sizes of the secondary peaks. These secondary peaks represent responses to optimal IPDs of the unit's best frequency for ITDs other than the best ITD. The distribution of secondary peak sizes in the AAr is comparable to that observed in the owl's ICX (Takahashi and Konishi, 1986) and OT (Cohen and Knudsen, unpublished observations), structures that are at the functional apex of the midbrain sound localization pathway (Knudsen et al., 1987). Moreover, like ICX and OT units, nearly all $\Lambda \Lambda \mathrm{r}$ units are tuned also for ILD, which contributes to the resolution of other spatial ambiguities and, therefore, to the specification of sound source location (Brainard et al., 1992).

For units in the AAr, as well as in the ICX and the OT, binaural tuning determines spatial tuning to a large extent. ITD and ILD vary systematically with the location of a sound source in space. In barn owls, as in all vertebrates, ITD changes with the azimuth of a source; and, for frequencies above $4 \mathrm{kHz}$, ILD changes with the elevation of a source (Fig. 4), due to an asymmetry of the owl's external ears (Payne, 1971; Knudsen et al., 1994). Consequently, unit tuning for ITD should contribute to the horizontal extent and position of the spatial receptive field, and unit tuning for ILD should contribute to the vertical extent and position of the spatial receptive field. Indeed, the luning of AAr, ICX and OT units for ITD and ILD predicts, respectively, the azimuth and elevation of these spatial receptive fields (Olsen et al., 1989; Brainard et al., 1992). 

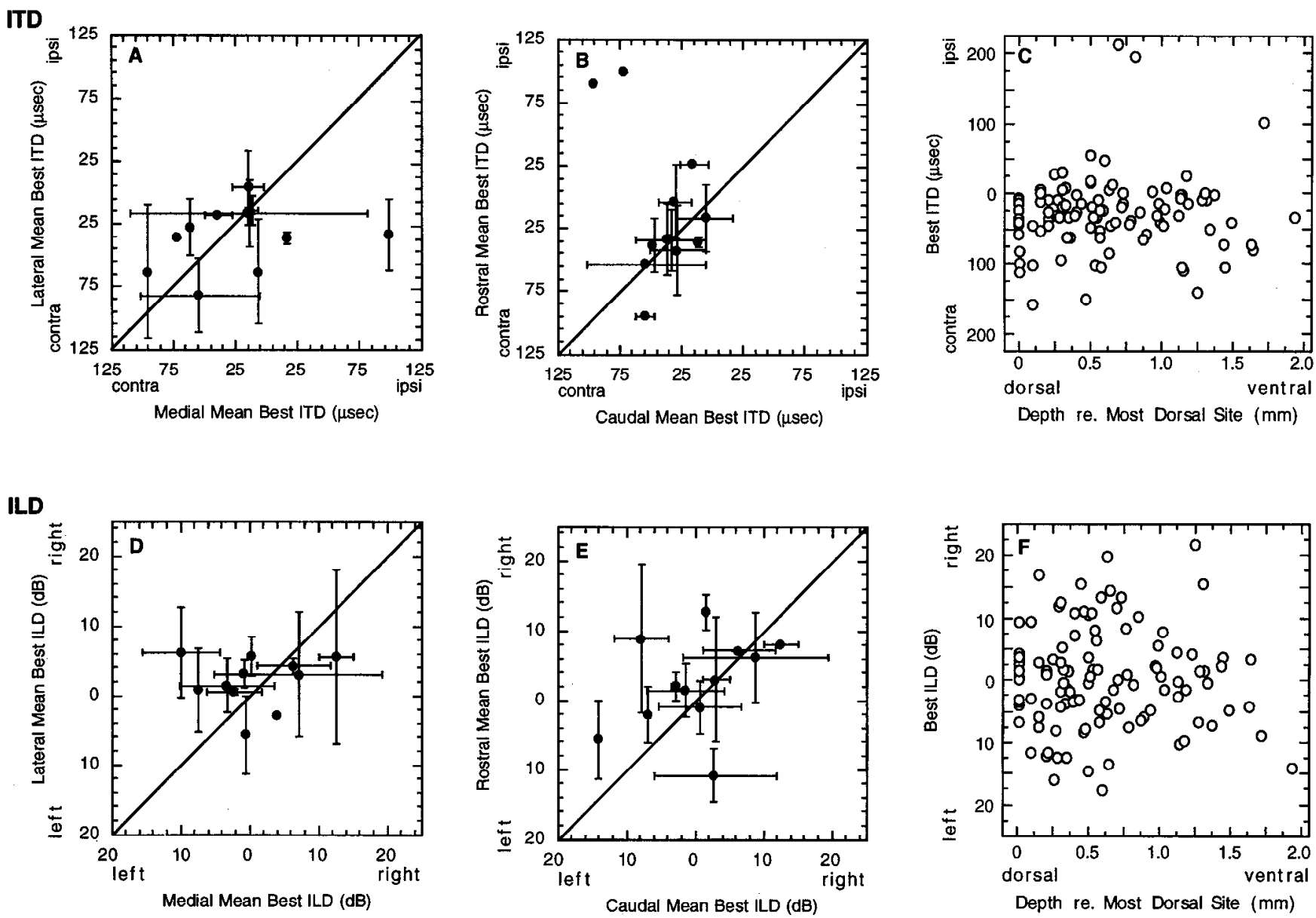

Figure 13. Analysis of topographic organization of binaural tuning properties in the AAr. $A$ and $B$, Mean best ITD for different mediolateral (A) and rostrocaudal $(B)$ pairs of electrode penetrations. For each pair of penetrations, the mean best ITD from the medial (caudal) penetration was plotted against the mean best ITD from its lateral (rostral) pair. The diagonal line represents no change in mean best ITD along each of these axes. If there were a topographic ordering of best ITDs, the data points would cluster either above or below this line. Instead, the data points are scattered randomly on both sides of the diagonal line indicating that there was no global, topographic representation of best ITDs along either of these axes. The error bars represent 1 SD from the mean. $C$, Best ITDs from different penetrations were plotted as a function of depth. No systematic progression of best ITDs was seen with increasing depth. $D$ and $E$, Mean best ILD from different mediolateral $(D)$ and rostrocaudal $(E)$ pairs of penetrations. For each pair of penetrations the mean best ILD from the medial (caudal) penetration was plotted against the mean best ILD from its lateral (rostral) pair. The diagonal line represents no change in mean best ILD along each of these axes. If there were a topographic ordering of best ILDs, the data points would cluster either above or below this line. Instead, the data points are scattered randomly on both sides of the diagonal line indicating that there was no global, topographic representation of best ILDs along either of these axes. The error bars represent 1 SD from the mean. $F$, Best ILDs from different penetrations were plotted as a function of depth. No systematic progression of best ILDs was seen with increasing depth.

Although the response properties of AAr sites are similar to those observed in the ICX and the OT, they are not the same. Both binaural tuning and spatial tuning in the AAr is broader than in these midbrain structures. In addition, AAr sites tend to respond, to some degree, to sounds originating from nearly any direction in space (Fig. 3). In contrast, ICX and OT units are inhibited by sounds originating from outside their restricted receptive fields (Knudsen and Konishi, 1978b; Brainard et al., 1992) A binaural correlate of the large receptive fields in the AAr is the high proportion of sites at which either ILD or ITD response modulation is less than $100 \%$ (Figs. 7,10 ). These sites, which constitute about $75 \%$ of AAr sites, can be driven by any value of ITD and/or ILD throughout the entire physiological range. Thus, many AAr sites combine spatial tuning within their receptive fields with nearly panoramic sensitivity.

Different functional organizations in the midbrain and forebrain

Another conspicuous difference between the AAr and the ICX and OT is their functional organization. In the ICX and OT, there is a single, continuous representation of binaural localization cues and, hence, of auditory space across each structure (Knudsen and Konishi, 1978a; Moiseff and Konishi, 1981a; Knudsen, 1982; Olsen et al., 1989; Mogdans and Knudsen, 1993): best ITDs change systematically along the rostrocaudal axis of each nucleus, forming maps of azimuth, and best ILDs change systematically along the dorsoventral axis of each nucleus, forming maps of elevation. In contrast, based on the distribution of best ITDs and best ILDs, which predicts reliably the azimuthal and elevational location of best areas (Fig. 4), there is no continuous map of azimuth or elevation in the AAr and, hence, no single map of space. Instead, units are clustered according to their binaural (and, therefore, spatial) tuning but the progression of tuning for ITD and ILD across the AAr does not change in a predictable manner (Figs. 14, 15).

The dramatic difference in functional organization between the AAr and the ICX and OT is surprising considering the intimate anatomical and physiological relationships that exist among these structures. The AAr projects directly to both the 
A

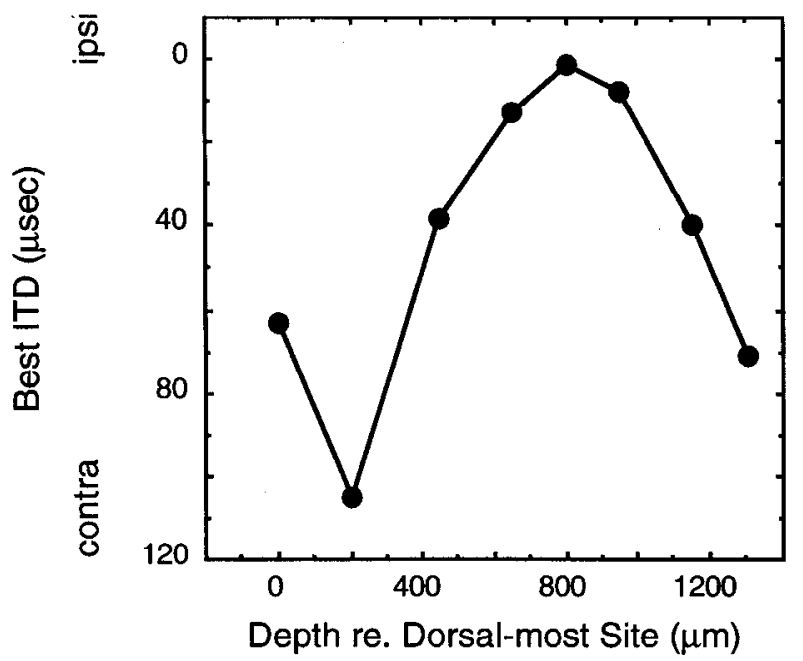

B

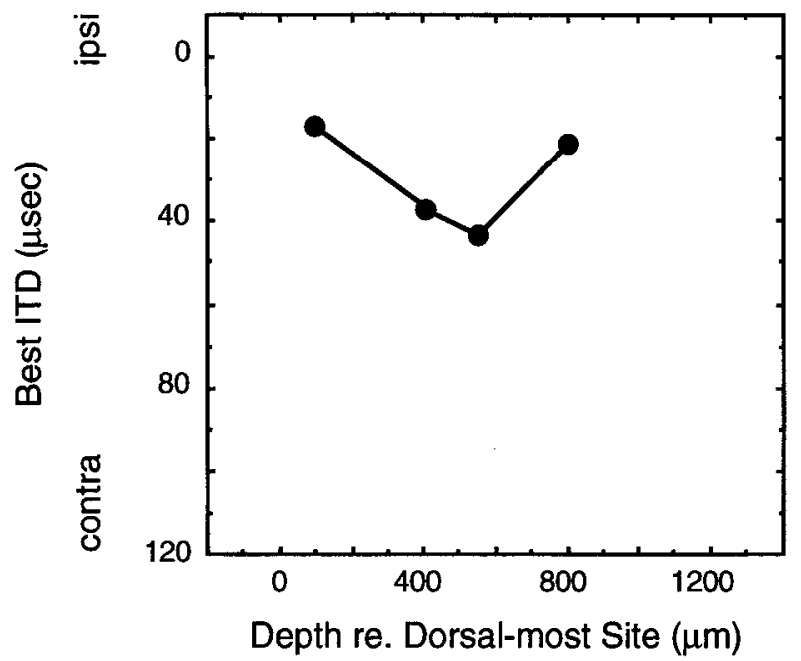

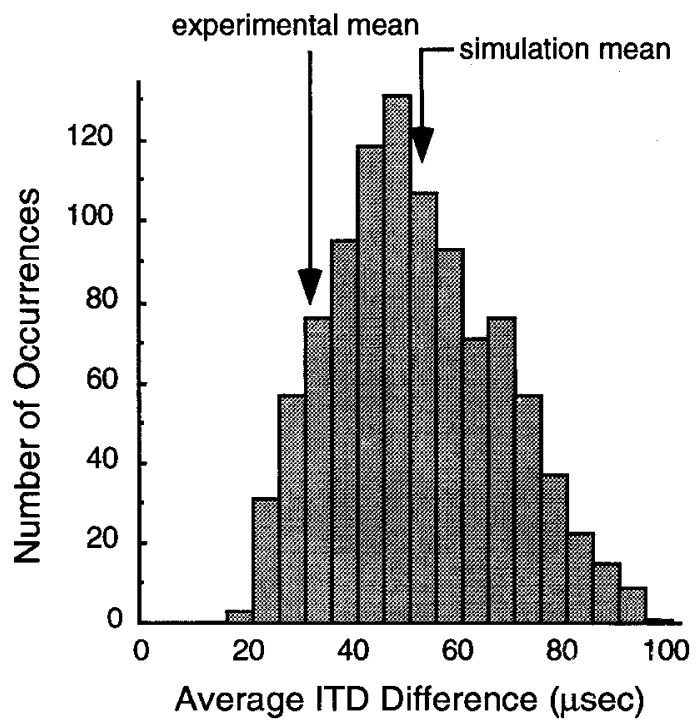

experimental mean

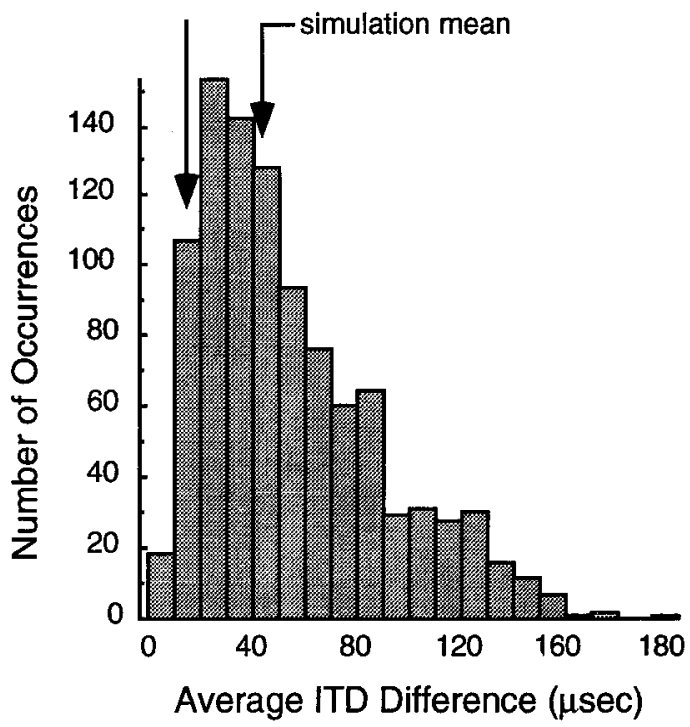

Figure 14. Best ITDs measured in individual dorsoventral electrode penetrations. A: Left, Best ITDs are plotted against recording depth, relative to the dorsal-most site in the penetration. In this penetration, best ITDs progressed smoothly with two reversals in the progression of values. Right, The distribution of mean best ITD differences from the Monte Carlo simulations for eight sites. The experimental mean for this penetration is less than the simulation mean, suggesting greater clustering than by chance. $B$ : Left, In this penetration, best l'IDs remained relatively constant with depth. Right, The distribution of mean best ITD differences from the Monte Carlo simulations for four sites. The experimental mean for this penetration is less than the simulation mean, suggesting greater clustering than by chance. The Monte Carlo distributions vary with the number of recording sites in a particular penetration.

ICX and the OT, and, in addition, the AAr and the OT project to the same nuclei in the midline brainstern tegmentum that are responsible for generating saccadic changes of gaze (Masino and Knudsen, 1992; Knudsen et al., 1995). Moreover, microstimulation in the AAr evokes saccadic movements of the head and eyes, independently of the OT (Knudsen et al., 1995). The pattern of anatomical connections and the similarity of the effects of microstimulation in the AAr and OT suggest that the AAr and OT represent similar levels of information processing, at least in the gaze control pathway.
Local organization of binaural tuning properties, as described here for the AAr, has been observed previously in the owl's basal ganglia (Cohen and Knudsen, 1994). Nearly all units in the auditory portion of the basal ganglia are tuned for both ITD and ILD. Best ITDs are clustered along the dorsoventral axis but change unpredictably along the rostrocaudal and mediolateral axes.

The local organization that is observed in the AAr and auditory basal ganglia of the owl is reminiscent of the "patchy" organization that has been described for somatosensory and 
A

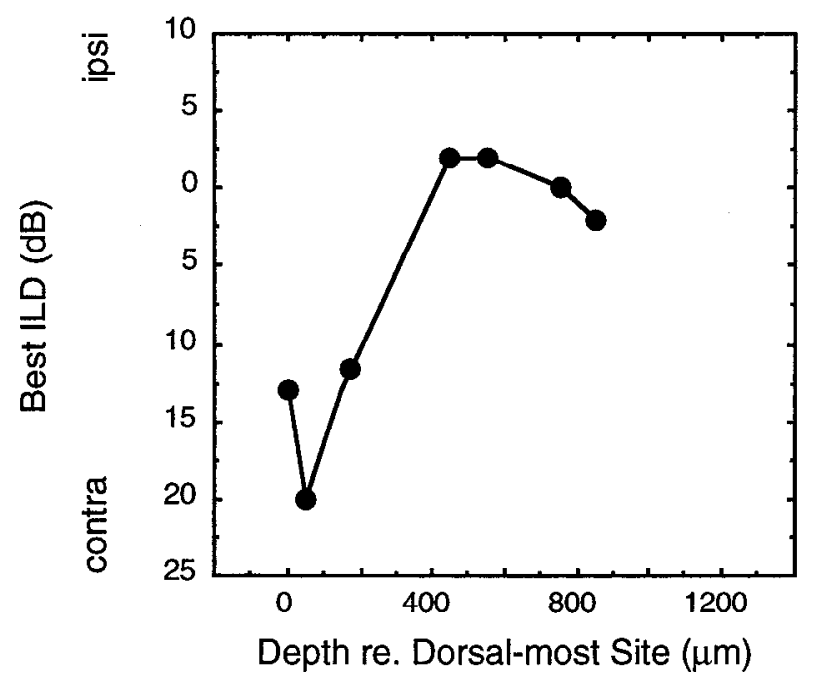

B

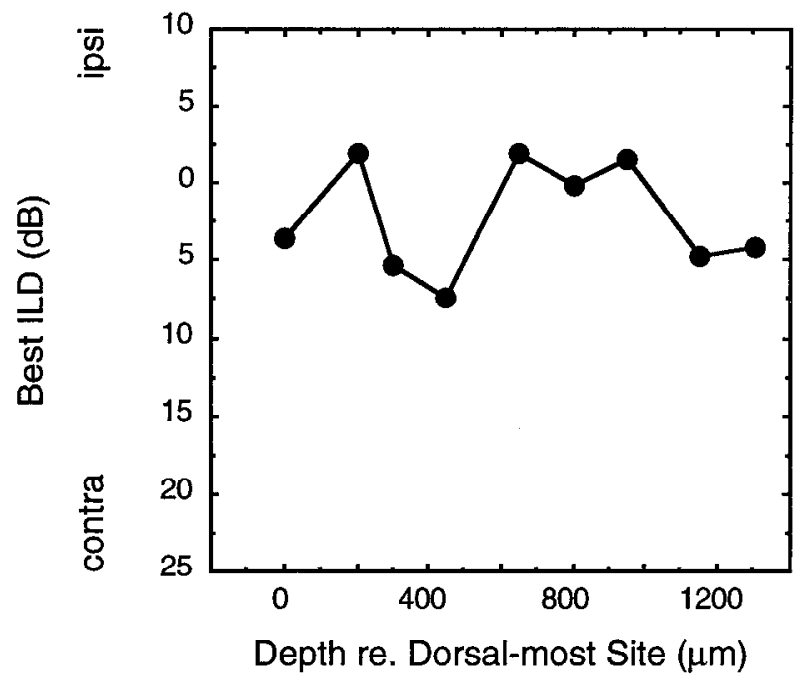

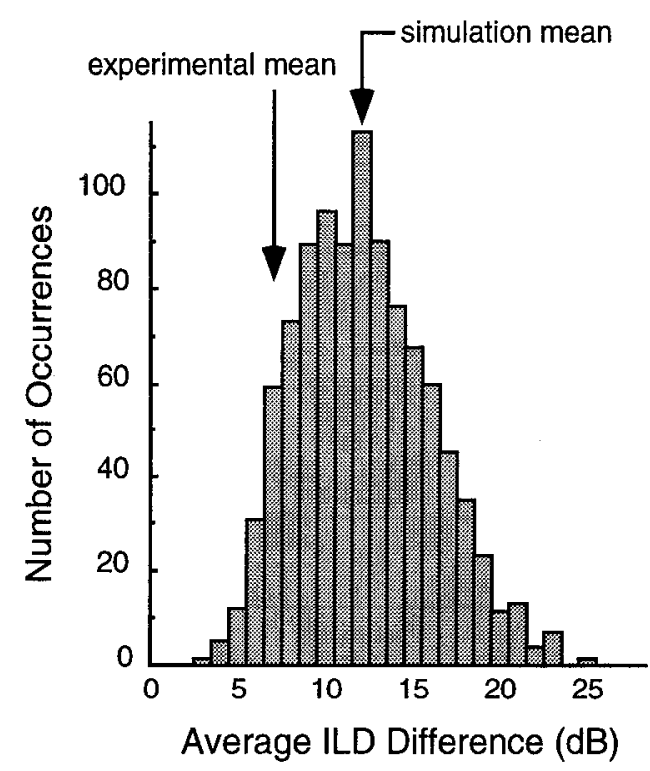

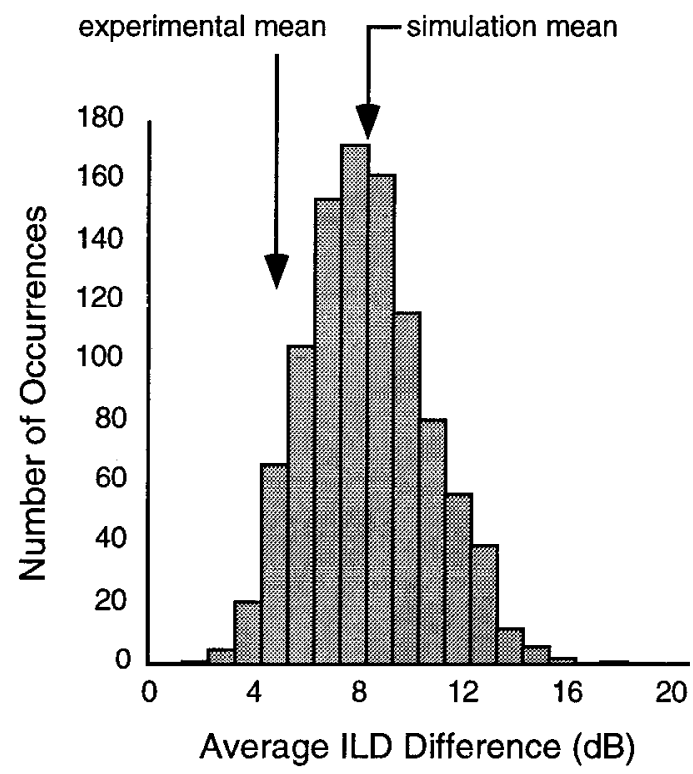

Figure 15. Best ILDs measured in individual dorsoventral penetrations. A: Left, Best ILDs are plotted against recording depth, relative to the dorsal-most site in the penetration. In this penetration, best ILDs progressed smoothly with two reversals in the progression of values. Right, The distribution of mean best ILD differences from the Monte Carlo simulations for seven sites. The experimental mean for this penetration is less than the simulation mean, suggesting greater clustering than by chance. B: Left, In this penetration, best ILDs remain relatively constant with depth. Right, The distribution of mean best ILD differences from the Monte Carlo simulations for nine sites. The experimental mean for this penetration is less than the simulation mean, suggesting greater clustering than by chance. The Monte Carlo distributions vary with the number of recording sites in a particular penetration.

movement-related activity in the cerebellum and basal ganglia of other species (Goldman and Nauta, 1977; Joseph et al., 1978; Shambes et al., 1978a,b; Kassl, 1980; Bower et al., 1981; Bower and Woolston, 1983; Crutcher and Delong, 1984; Welker, 1987; Bower and Kassel, 1990; Flaherty and Graybiel, 1994). It has been postulated that this type of organization is optimal for those behaviors that involve local and global interactions (Nelson and Bower, 1990). For example, the patchiness of the somatosensory representation in the cerebellum may facilitate the analysis of local sensory information within the more global context of a movement (Bower and Kassel, 1990; Nelson and Bower, 1990). In the basal ganglia, the patchy organization of movement-related activity is similarly believed to facilitate local and global interactions, such as those that are required for grasping (Nelson and Bower, 1990) or sensorimotor learning (Aosaki et al., 1994; Flaherty and Graybiel, 1994). 
Speculations on the basis for differences in functional organization in the forebrain and midbrain

The primary role of auditory activity in the barn owl OT may well be for the control of gaze (Knudsen et al., 1993). In contrast, auditory activity in the AAr probably contributes to a wide variety of sensorimotor tasks more complicated than gaze control. These tasks might include the selection of particular auditory stimuli for attention, the encoding of stimulus locations that must be remembered while making complicated movements, or the selection or guidance of complicated movements in response to particular auditory stimuli. The computations that contribute to these complex functions require the integration of auditory spatial information with information about body position and changes in body position and with information from memory stores and limbic structures. It is possible that for the mediation of complex or multiple tasks a local organization rather than a global auditory space map is the optimal format for the representation of auditory space.

The same principle may apply to the representations of auditory spatial information in the forehrain and midbrain of mammals as well. Auditory space maps have been sought in a variety of mammalian species. Auditory space maps have been found in the midbrain ICX and OT (King and Palmer, 1983; Middlebrooks and Knudsen, 1984; King and Hutchings, 1987; Binns, 1992). They have not been found, however, anywhere in the forebrain. Instead, units in the mammalian forebrain tend to cluster according to their binaural tuning properties (Middlebrooks et al., 1980; Middlebrooks and Pettigrew, 1981; Rajan et al., 1990; Kelly and Judge, 1993). It is possible that in mammals, as in owls, forebrain structures that participate in complex or various behaviors may not contain mapped representations of auditory space.

\section{References}

Aosaki T, Graybiel AM, Kimura M (1994) Effect of the nigrostriatal dopamine system on acquired neural responses in the striatum of behaving monkeys. Science $265: 412-415$.

Binns KE, Grant S, Withington DJ, Keating MJ (1992) A topographic representation of auditory space in the external nucleus of the inferior colliculus of the guinea pig. Brain Res 589:231-242.

Bower JM, Kassel J (1990) Variability in tactile projection patterns to cerebellar folio crus IIA of the Norway rat. J Comp Neurol 302:768778.

Bower JM, Woolston DC (1983) Congruence of the spatial organization of tactile projections to the granule cell and Purkinje cell layers of the cerebellar hemispheres of the albino rat: the vertical organization of the cerebellar cortex. J Neurophysiol 49:745-766.

Bower JM, Becrmann DH, Gibson JM, Shambes GM, Wclker W (1981) Principles of organization of a cerebro-cerebellar circuit. Micromapping the projection from cerebral (SI) to cerebellar (granule cell layer) tactile areas of rats. Brain Behav Evol 18:1-18.

Brainard MS, Knudsen EI, Esterly SD (1992) Neural derivation of sound location: resolution of spatial ambiguities in binaural cues. $\mathbf{J}$ Acoust Soc Am 91:1015-1017.

Bruce CJ (1990) Integration of sensory and motor signals in primate frontal eye fields. In: From signal and sense: local and global order in perceptual maps (Edelman GM, Gall WE, Cowan WM, eds), pp 261-314. New York: Wiley-Liss.

Brugge JF, Dubrovsky NA, Aitkin LM, Anderson DJ (1969) Sensitivity of single neurons in auditory cortex of cat to binaural tonal stimulation; effects of varying interaural time and intensity. $\mathbf{J}$ Neurophysiol 32:1005-1024.

Bugbee NM (1979) The basal ganglia-tectal pathway: its role in visually-guided behavior in the pigeon (Columba livia). Ph.D. dissertation, University of Maryland.

Carr CE, Konishi M (1988) Axonal delay lines for time measurement in the owl's brainstem. Proc Natl Acad Sci USA 85:8311-8315.

Casagrande VA, Diamond IT (1974) Ablation study of the superior colliculus in the tree shrew (Tupaia glis). J Comp Neurol 156:207238.

Clarey JC, Barone P, Imig TJ (1992) Physiology of thalamus and cortex. In: The mammalian auditory pathway: neurophysiology (Popper AN, Fay RR), pp 232-334. New York: Springer.

Cohen YE, Knudsen EI (1994) Auditory tuning for spatial cues in the barn owl basal ganglia. J Neurophysiol 72:285-298.

Cook D, Kesner RP (1988) Caudate nucleus and memory for egocentric localization. Behav Neural Biol 49:332-343.

Crutcher MD, DeLong MR (1984) Single cell studies of the primate putamen. I. Functional organization. Exp Brain Res 53:233-243.

Flaherty AW, Graybiel AM (1994) Input-output organization of the sensorimotor striatum in the squirrel monkey. J Neurosci 14:599-610.

Fujita I, Konishi M (1991) The role of GABAergic inhibition in processing of interaural time difference in the owl's auditory system. $J$ Neurosci 11:722-729.

Goldberg ME, Segraves MA (1989) The visual and frontal cortices. In: The neurobiology of saccadic eye movements (Wurtz RH, Goldberg MF, eds), pp 283-313. Amsterdam: Flsevier.

Goldman PS, Nauta WJH (1977) An intricately patterned pre-frontalcaudate projection in the rhesus monkey. J Comp Neurol 171:369386.

Goodman I, Zacny J, Osman A, Azzaro A, Donovan C (1982) Lesionproduced telencephalic catecholamine imbalances and altered operant pecking rates in pigeons. Physiol Behav 29:1045-1050.

Hikosaka O (1991) Role of the forebrain in oculomotor function. In: Progress in brain research (Holstege G, ed), pp 101-106. Amsterdam: Elsevier.

Hirsch JA, Chan JCK, Yin TCT (1985) Responses of neurons in the cat's superior colliculus to acoustic stimuli. I. Monaural and binaural response properties. J Neurophysiol 53:726-745.

Irvine DRF, ed (1986) Progress in sensory physiology, Vol 7, The auditory brainstem. New York: Springer.

Jay MF, Sparks DL (1984) Auditory receptive fields in primate superior colliculus shift with changes in eye position. Nature 309:345-347.

Joseph JW, Shambes GM, Gibsun JM, Welker W (1978) Tactile projections to granule cells in caudal vermis of the rat's cerebellum. Brain Behav Evol 15:141-149.

Kassl J (1980) Superior colliculus projections to tactile areas of rat cerebellar hemispheres. Brain Res 202:291-305.

Kelly JB, Judge PW (1993) Binaural organization of primary auditory cortex in the ferret (Mustela putorius). J Neurophysiol 71:904-913.

Kennard C, Lueck CJ (1989) Oculomotor abnormalities in disease of the basal ganglia. Rev Neurol 145:587-595.

King AJ, Hutchings ME (1987) Spatial response properties of acoustically response neurons in the superior colliculus of the ferret: a map of auditory space. J Neurophysiol 57:596-624.

King AJ, Palmer AR (1983) Cells response to free-field auditory stimuli in guinea-pig superior colliculus: distribution and response properties. J Physiol (Lond) 342:361-381

Knudsen EI (1982) Auditory and visual maps of space in the optic tectum of the owl. J Neurosci 2:1177-1194.

Knudsen EI (1985) Experience alters the spatial tuning of auditory units in the optic tectum during a sensitive period in the barn owl. J Neurosci 5:3094-3109.

Knudsen EI, Konishi M (1978a) A neural map of auditory space in the owl. Science 200:795-797.

Knudsen EI, Konishi M (1978b) Center-surround organization of au ditory receptive fields in the owl. Science 202:778-780.

Knudsen EI, Konishi M, Pettigrew JD (1977) Receptive fields of auditory neurons in the owl. Science 198:1278-1280.

Knudsen EI, Blasdel GG, Konishi M (1979) Sound localization by the barn owl measured with the search coil technique. J Comp Physiol $133: 1-11$.

Knudsen EI, du Lac S, Esterley SD (1987) Computational maps in the brain. Annu Rev Neurosci 10:41-65.

Knudsen EI, Esterly SD, du Lac S (1991) Stretched and upside-down maps of auditory space in the optic tectum of blind-reared owls: acoustic basis and behavioral correlates. J Neurosci 11:1727-1747.

Knudsen EI, Knudsen PF, Masino, T (1993) Parallel pathways mediating both sound localization and gaze control in the forebrain and midbrain of the barn owl. J Neurosci 13:2837-2852.

Knudsen EI, Esterly SD, Olsen JF (1994) Adaptive plasticity of the auditory space map in the optic tectum of adult and baby barn owls in response to external ear modification. J Neurophysiol 71:79-94. 
Knudsen EI, Cohen YE, Masino T (1995) Characterization of a forebrain gaze field in the archistriatum of the barn owl: microstimulation and anatomical connections. J Neurosci 15:5139-5151.

Konishi M (1973) How the owl tracks its prey. Am Sci 61:414-424.

Konishi M, Takahashi T, Wagner H. Sullivan WE, Carr CE (1988) Neurophysiological and anatomical substrates of sound localization in the owl. In: Auditory function (Edelman G, Gall W, Cowan W, eds), pp 721-746. New York: Wiley.

Masino T, Knudsen EI (1992) Anatomical pathways from the optic tectum to the spinal cord subserving orienting movements in the barn owl. Exp Brain Res 92:194-208.

Middlebrooks JC (1987) Binaural mechanisms of spatial tuning in the cat's superior colliculus distinguished using monaural occlusion. $\mathbf{J}$ Neurophysiol 57:688-701.

Middlebrooks JC, Knudsen El (1984) A neural code for auditory space in the cat's superior colliculus. J Neurosci 4:2621-2634.

Middlebrooks JC, Pettigrew JD (1981) Functional classes of neurons in primary auditory cortex of the cat distinguished by sensitivity to sound location. J Neurosci 1:107-120.

Middlebrooks JC, Dykes RW, Merzenich MM (1980) Binaural response-specific bands in primary auditory cortex (Al) of the cat: topographical organization orthogonal to isofrequency contours. Brain Res 181:31-48.

Mogdans J, Knudsen EI (1993) Early monaural occlusion alters the neural map of interaural level difference in the inferior colliculus of the barn owl. Brain Res 619:29-38.

Moiseff A, Konishi M (1981a) Neuronal and behavioral sensitivity to binaural time differences in the owl. J Neurosci 1:40-48.

Moiseff A, Konishi M (1981b) The owl's interaural pathway is not involved in sound localization. J Comp Neurol 144:299-304.

Neff WD, Diamond IT, Casseday JH (1975) Behavioral studies of auditory discrimination: central nervous system. In: Handbook of sensory physiology, Vol V/2 (de Reuck AVS, Knight J, eds), pp 307400. New York: Springer.

Nelson ME, Bower JM (1990) Brain maps and parallel computers. Trends Neurosci 13:403-408.

Olsen JF, Knudsen EI, Esterly SD (1989) Neural maps of interaural time and intensity differences in the optic tectum of the barn owl. J Neurosci 9:2591-2605.

Packard MG, Hirsh R, White NM (1989) Differential effects of fornix and caudate lesions on two radial maze tasks: evidence for multiple memory systems. J Neurosci 9:1465-1472.

Payne RS (1971) Acoustic location of prey by barn owls (Tyto alba). J Exp Biol 54:535-573.

Potegal M (1969) Role of the caudate nucleus in spatial orientation of rats. J Comp Physiol Psychol 69:756-764.

Potegal M (1971) A note on spatial-motor deficits in patients with Huntington's disease: a test of a hypothesis. Neuropsychologia 9:233-235.

Rajan R, Aitkin LM, Irvine DRF (1990) Azimuthal sensitivity of neu- rons in primary auditory cortex of cats. II. Organization along frequency-band strips. J Neurophysiol 64:888-902.

Rieke GK (1980) Kainic acid lesions of pigeon paleostriatum: a model for study of movement disorders. Physiol Behav 24:683-687.

Rieke GK (1981) Movement disorders and lesions of pigeon brain stem analogues of basal ganglia. Physiol Behav 26:379-384.

Rieke GK (1982) The TPc, the avian substantia nigra: pharmacology and behavior. Physiol Behav 28:755-763.

Sanberg PR, Mark RF (1983) The effect of striatal lesions in the chick on haloperidol-potentiated tonic immobility. Neuropharmacology 22: 253-257.

Schneider GE (1969) Two visual systems. Science 163:895-902.

Shambes GM, Beerman DH, Welker W (1978a) Multiple tactile areas in cerebellar cortex: another patchy cutaneous projection to granule cell columns in rat. Brain Res 157:123-128.

Shambes GM, Gibson JM, Welker W (1978b) Fractured somatotopy in granule cell tactile areas of rat cerebellar hemispheres revealed by micromapping. Brain Behav Evol 15:94-140.

Sprague JM, Meikle THJ (1965) The role of the superior colliculus in visually guided behavior. Exp Neurol 11:115-146.

Stein BE, Meredith MA (1993) The merging of the senses. Cambridge, MA: MIT Press.

Stein BE, Meredith MA, Huneycutt WS, McDade L (1989) Behavioral indices of multisensory integration: orientation to visual cues is affected by auditory stimuli. J Cognit Neurosci 1:1-12.

Takahashi T, Konishi M (1986) Selectivity for interaural time difference in the owl's midbrain. J Neurosci 6:3413-3422.

Wagner H (1993) Sound-localizing deficits induced by lesions in the barn owl's auditory space map. J Neurosci 13:371-386.

Welker W (1987) Spatial organization of somatosensory projections to granule cII cerebellar cortex: functional and connectional implications of fractured somatotopy (summary of Wisconsin studies). In: New concepts in cerebellar neurobiology (King JS, ed), pp 239-280. New York: Liss.

Wesp R, Goodman I (1978) Fixed interval responding by pigeons following damage to corpus striatal and limbic structures (paleostriatal complex and parolfactory lobe). Physiol Behav 20:571-577.

Wise LZ, Irvine DR (1983) Interaural intensity difference sensitivity based on facilitatory binaural interaction in cat superior colliculus. Hear Res 16:181-187.

Wise LZ, Irvine DR (1984) Auditory response properties of neurons in deep layers of cat superior colliculus. J Neurophysiol 49:674-685.

Wise LZ, Irvine DR (1985) Topographic organization of interaural intensity difference sensitivity in deep layers of cat superior colliculus: implications for auditory spatial representation. J Neurophysiol 54: $185-211$

Yin TCT, Kuwada S (1984) Neuronal mechanisms of binaural interaction In: Dynamic aspects of neocortical function (Edelman GM, Gall WE, Cowan WM, eds), pp 263-314. New York: Wiley.

Zeier H, Karten HJ (1971) The archistriatum of the pigeon: organization of afferent and efferent connections. Brain Res 31:313-326. 